\title{
Pricing Carbon Emissions in China
}

\author{
Chia-Lin Chang \\ Department of Applied economics, Department of Finance \\ National Chung Hsing University, Taiwan
}

\section{Te-Ke Mai}

Department of Economics

National Tsing Hua University, Taiwan

Michael McAleer

Department of Finance Asia University, Taiwan and

Discipline of Business Analytics University of Sydney Business School, Australia

And Econometric Institute, Erasmus School of Economics

Erasmus University Rotterdam, The Netherlands and

Department of Economic Analysis and ICAE,

Complutense University of Madrid, Spain andInstitute of Advanced Sciences

Yokohama National University, Japan

\section{Instituto \\ Complutense de Análisis Económico}

\begin{abstract}
The purpose of the paper is to provide a clear mechanism for determining carbon emissions pricing in China as a guide to how carbon emissions might be mitigated to reduce fossil fuel pollution. The Chinese Government has promoted the development of clean energy, including hydroelectric power, wind power, and solar energy generation. In order to involve companies in carbon emissions control, a series of regional and provincial carbon markets have been established since 2013. Since China's carbon market was established in 2013 and mainly run domestically, and not necessarily using market principles, there has been almost no research on China's carbon price and volatility. This paper provides an introduction to China's regional and provincial carbon markets, proposes how to establish a national market for pricing carbon emissions, discusses how and when these markets might be established, how they might perform, and the subsequent prices for China's regional and national carbon markets. Power generation in manufacturing consumes more than other industries, with more than $40 \%$ of total coal consumption. Apart from manufacturing, the northern China heating system also relies on fossil fuels, mainly coal, which causes serious pollution. In order to understand the regional markets well, it is necessary to analyze the energy structure in these regions. Coal is the primary energy source in China, so that provinces that rely heavily on coal receive a greater number of carbon emissions permits from the Chinese Government. In order to establish a national carbon market for China, a detailed analysis of eight important regional markets will be presented. The four largest energy markets, namely Guangdong, Shanghai, Shenzhen and Hubei, traded around $82 \%$ of the total volume and $85 \%$ of the total value of the seven markets in 2017 , as the industry structure of the western area is different from that of the eastern area. The China National Development and Reform Commission has proposed a national carbon market, which can attract investors and companies to participate in carbon emissions trading. This important issue will be investigated in the paper.
\end{abstract}

Keywords Pricing Chinese Carbon Emissions, National Pricing Policy, Energy, Volatility, Energy Finance, Provincial Decisions.

.JEL Classification $\quad$ C22, C58, G12, Q35, Q48.

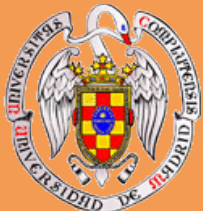

UNIVERSIDAD

COMPLUTENSE MADRID

ISSN: 2341-2356

WEB DE LA COLECCIÓN: http://www.ucm.es/fundamentos-analisis-economico2/documentos-de-trabajo-del-icaeWorking papers are in draft form and are distributed for discussion. It may not be reproduced without permission of the author/s. 


\title{
Pricing Carbon Emissions in China*
}

\author{
Chia-Lin Chang \\ Department of Applied Economics \\ Department of Finance \\ National Chung Hsing University, Taiwan \\ Te-Ke Mai \\ Department of Economics \\ National Tsing Hua University, Taiwan

\section{Michael McAleer **} \\ Department of Finance \\ Asia University, Taiwan \\ and \\ Discipline of Business Analytics \\ University of Sydney Business School, Australia \\ and \\ Econometric Institute, Erasmus School of Economics \\ Erasmus University Rotterdam, The Netherlands \\ and \\ Department of Economic Analysis and ICAE \\ Complutense University of Madrid, Spain \\ and \\ Institute of Advanced Studies \\ Yokohama National University, Japan
}

January 2018

\footnotetext{
* For financial support, the first author wishes to acknowledge the National Science Council, Ministry of Science and Technology (MOST), Taiwan, and the third author is grateful to the Australian Research Council and the National Science Council, Ministry of Science and Technology (MOST), Taiwan.

** Corresponding author: michael.mcaleer@gmail.com
} 


\begin{abstract}
The purpose of the paper is to provide a clear mechanism for determining carbon emissions pricing in China as a guide to how carbon emissions might be mitigated to reduce fossil fuel pollution. The Chinese Government has promoted the development of clean energy, including hydroelectric power, wind power, and solar energy generation. In order to involve companies in carbon emissions control, a series of regional and provincial carbon markets have been established since 2013. Since China's carbon market was established in 2013 and mainly run domestically, and not necessarily using market principles, there has been almost no research on China's carbon price and volatility. This paper provides an introduction to China's regional and provincial carbon markets, proposes how to establish a national market for pricing carbon emissions, discusses how and when these markets might be established, how they might perform, and the subsequent prices for China's regional and national carbon markets. Power generation in manufacturing consumes more than other industries, with more than $40 \%$ of total coal consumption. Apart from manufacturing, the northern China heating system also relies on fossil fuels, mainly coal, which causes serious pollution. In order to understand the regional markets well, it is necessary to analyze the energy structure in these regions. Coal is the primary energy source in China, so that provinces that rely heavily on coal receive a greater number of carbon emissions permits from the Chinese Government. In order to establish a national carbon market for China, a detailed analysis of eight important regional markets will be presented. The four largest energy markets, namely Guangdong, Shanghai, Shenzhen and Hubei, traded around $82 \%$ of the total volume and $85 \%$ of the total value of the seven markets in 2017, as the industry structure of the western area is different from that of the eastern area. The China National Development and Reform Commission has proposed a national carbon market, which can attract investors and companies to participate in carbon emissions trading. This important issue will be investigated in the paper.
\end{abstract}

Keywords: Pricing Chinese Carbon Emissions, National Pricing Policy, Energy, Volatility, Energy Finance, Provincial Decisions.

JEL: C22, C58, G12, Q35, Q48. 


\section{Introduction}

In the early 1990's, international community began paying attention to climate change. Since the signing of the "United Nations Framework Convention on Climate Change" in 1992, more and more action had been taken to address climate change. A series of international documents have been signed to help different countries work together to face this challenge, including the "Kyoto Protocol" signed in 1997, "Copenhagen Accord" signed in 2009, and "Paris Agreement" signed in 2015. These documents provide a base for international cooperation to deal with climate change. Many countries have begun to reduce their domestic carbons emission to try to control climate change.

As one of the biggest economies, biggest carbon emitters in the world, and as a member of the United Nations Permanent Council, China needs to take action to perform its duty and accept responsibility for one of the major problems presently facing the international community. The Chinese Government has promoted the development of clean energy, including hydroelectric power, wind power, and solar energy generation. In order to involve companies in carbon emissions control, a series of regional and provincial carbon markets have been established since 2013. Recently, the China National Development and Reform Commission proposed establishing a national carbon market. At present, the project is waiting permission from the Government for implementation.

\section{Brief Literature Discussion}

There are some papers and reports about carbon emissions pricing and price and volatility spillovers between carbon market and energy market. Daskalakis et al. (2009) developed an empirical and theoretical framework for intra-phase and inter-phase futures pricing and hedging. The empirical analysis suggests that the carbon permit spot price has jumps and is non-stationary. The authors described appropriate pricing methods for the intra-phase and inter-phase options on futures.

Zhang and Sun (2016) apply a Full BEKK multivariate conditional volatility model to analyze the time-varying correlations and dynamic spillovers between the Euro carbon market and fossil fuel market. Chang et al (2017) use daily data for EU carbon futures, US spot prices, and spot and futures prices of oil and coal to analyze volatility spillovers and Granger causality. Since China's carbon market was established in 2013 and mainly run domestically, and not necessarily using market principles, there 
has been almost no research on China's carbon price and volatility. The following general references are useful for purposes of understanding some aspects of carbon pricing in China. Chang (2010) examined a multivariate causality test of carbon dioxide emissions, energy consumption and economic growth in China. Chen (2005) evaluated the costs of mitigating carbon emissions in China using MARKAL-MACRO Modeling. Daskalakis et al. (2009) provided evidence from modelling CO2 emissions allowance prices and derivatives in Europe. Gregg et al. (2008) analysed the emissions patterns of China as the world leader in $\mathrm{CO} 2$ emissions from fossil fuel consumption and cement production.

Li and Colombier (2009) viewed the managing of carbon emissions in China through building energy efficiency. Liu et al. (2015) reviewed China's carbon-emissions trading, and the challenges for the future. Nam et al. (2014) compared the synergy between pollution and carbon emissions control for China and the USA. Tang et al. (2015) evaluated the carbon emissions trading scheme exploration in China using a multi-agent-based model. Xiong et al. (2017) compared the allowance mechanism of China's carbon trading pilots with alternative schemes in the EU and California. Zhang (2015) reformulated the low-carbon green growth strategy in China. Zhang et al. (2014) considered emissions trading in China in terms of progress and future prospects. Zhang et al. (2014) used evidence from the Shapley value model to understand regional allocations of carbon emissions quotas in China.

In view of the discussion presented above, this paper provides an introduction to China's regional and provincial carbon markets, proposes how to establish a national market for pricing carbon emissions, discusses how and when these markets might be established, how they might perform, and the subsequent prices for China's regional and national carbon markets.

\section{Chinese Reliance on Fossil Fuels}

China has the largest population and consumes the largest amount of energy in the world. Of the total energy China consumed in 2015, 87.9\% of the total consumption was fossil fuels, with only $12.1 \%$ from clean energy, including nuclear, hydro and wind. From Table 1, the primary fossil fuel for China is coal, which accounting for $63.7 \%$, followed by oil at $18.3 \%$, and natural gas at $5.9 \%$. Of the three fossil fuels, coal contributes the most to carbon emissions.

China is a manufacturing country, with $40.9 \%$ of GDP contributed by the 
manufacturing sector (in 2015), with nearly 30\% of employment in the manufacturing industry. As a result, the Chinese economy relies heavily on manufacturing, and hence on fossil fuels.

As a result, the manufacturing industry consumes the major part of energy. According to the National Bureau of Statistics of China, in 2015 the manufacturing industry consumed $3,756,500,000$ tons of coal (94.6\% of total coal consumption in 2015), $540,524,300$ tons of oil (99.93\% of total oil crude consumption), and 123,448 billion cubic meters of natural gas (63.90\% of total natural gas consumption). Moreover, $70 \%$ of electricity is produced by fossil fuel. Without electricity, it is not possible to have a manufacturing industry. Power generation in manufacturing consumes more than other industries, with more than $40 \%$ of total coal consumption.

China consumes substantial quantities of fossil fuel, and also produces substantial quantities of fossil fuels, apart from oil. China is one of the biggest producers of coal in the world, and produces $94.35 \%$ of the coal it consumes. China also exports coal. Only 5,338 thousand tons were exported in 2015, which is a small part of total production, which is 3,970,738 million tons. Production of coal in China over the past three years has been decreasing directly as a result of production control by the Government. In order to reduce carbon emissions and excess capacity of coal, the Chinese Government has shut down several mines and reduced the working days of coal enterprises from 330 days to 276 days each year.

The production of Chinese coal decreased from July 2015 (305.59 million tons) to July 2016 (263.75 million tons), and then increased, reaching 310.97 million tons in February 2016, finally decreasing to 283.54 million tons. Therefore, China has reduced its production of coal during the past 36 months. This may be evidence that China is trying to control carbon emissions.

China also produces most of the natural gas it consumes. $81.4 \%$ of the total gas consumption of China is produced domestically. China also needs to import some natural gas, nearly 18\% of total consumption. From Figure 1, gas production has been increasing, with decreases in February 2016 and March 2017. This is because gas is less polluting, so China is trying to reduce the use of coal and increase the use of gas and oil.

China is rich in coal and natural gas resources, but it does not produce much oil. In 2015, almost 70\% of the Chinese oil consumption was imported. From Figure 2, oil 
importation and the oil import ratio of China have both been increasing from 2000. It seems that imports and the import ratio will continue to increase. China relies on importing oil. Figure 2 also shows that China uses increasing quantities of oil, which is less polluting than coal.

Apart from manufactory, the northern China heating system also relies on fossil fuels, mainly coal. However, heating with coal causes serious pollution, so the China State Council and the China National Development and Reform Commission has required regions to reduce their use of coal from 2013. According to the China National Development and Reform Commission, China’s coal consumption declined 2.9\% in 2014 and $3.7 \%$ in 2015.

Coal continues to be the most importance fossil fuel in China at present. It is a difficult task for China to substitute coal with natural gas in a short period. A crisis occurred in 2017, due to a lack of supply of natural gas (nearly $20 \%$ of total gas), prices soared, and businesses and residents across China's industrial heartland were badly affected.

\section{Energy Consumption Structures in Eight Regions in China}

Of the three fossil fuels, same unit of coal produces greater carbon dioxide than do oil and gas. In order to understand the regional markets well, it is necessary to analyze the energy structure in these regions.

Table 2 shows that coal is the primary energy source for Hubei, Chongqing, Tianjin, Fujian, Guangdong and Shanghai, which indicates that coal is the most important fossil fuel for China. Among them, Hubei relies most heavily on coal, accounting for $63.3 \%$ of total fossil fuel consumption, followed by Chongqing at 57.7\%. One-half of total consumption of energy in Tianjin and Fujian is coal. For Guangdong and Shanghai, coal consumption account for $42.3 \%$ and $36.4 \%$ of the total consumption, respectively. There is substantial manufacturing in these provinces. As a result, they consume much coal, which is cheaper than oil. These provinces rely heavily on coal, and the Central Government distributes a greater number of carbon emissions permits to these provinces. Shenzhen and Beijing do not rely much on coal, and hence receive fewer carbon emissions permits from the Central Government.

For oil consumption, 33.5\% of fossil fuel consumed by Beijing and 34.9\% consumed by Shanghai is oil, which are the highest two provinces based on oil. Beijing has 
suffered severe smog for a long time, so it consumes more oil, gas and electricity than coal. Oil is the most important fossil fuel for Beijing, and the second most important fossil fuel for Shanghai, Guangdong, Tianjin, Hubei, Chongqing and Fujian. Coal consumption accounted for 28\% of total consumption in Tianjin, 27.3\% in Guangdong, 24.6\% in Fujian, $18.0 \%$ in Hubei, and $14.6 \%$ in Chongqing. For Shenzhen, the ratio is unbelievably low at $2.8 \%$, so that Shenzhen consumes almost zero oil. This is because of the industry structure in Shenzhen, which is adjusting the industry structure. High technology industries with low energy-consumption are beginning to replace the high energy-consumption and highly polluted industries. As a result, Shenzhen does not rely much on coal and oil.

Natural gas is less polluting than oil and coal because of the industry structure and upgrading, Shenzhen industries have become less polluting, and natural gas was the second most important energy source in Shenzhen. The natural gas consumption ratio in Shenzhen was the highest of the eight regions, followed by Beijing at $29.0 \%$. For Chongqing and Shanghai, the ratios were $14.4 \%$ and $10.0 \%$, respectively. The other four provinces do not consume much gas, at relatively low figures of 9.3\%, 6.4\%, 5.0\% and 3.0\%. A high natural gas consumption rate means lower carbon emissions.

For electricity consumption, the highest ratio was 39.3\% for Shenzhen, followed by Guangdong, Beijing, Fujian and Shanghai at 24.0\% 23.8\%, 19.9\% and 18.6\%, respectively. The electricity consumption rate for Hubei is $15.7 \%$. The lowest electricity consuming province is Tianjin, which is only $12.7 \%$ of total energy consumption.

From the eight provincial energy consumption structures, energy consumption of Shenzhen is the most environmentally friendly, with more than $70 \%$ of energy consumption based on natural gas and electricity. Consequently, the Shenzhen Government can set the highest carbon control participation requirements, which is more than 3000 tons of carbon emissions per year. Beijing is another environmentally friendly energy consuming province, where more than $50 \%$ of total consumption is gas and electricity, while only $13.7 \%$ is coal. Guangdong and Shanghai rely on coal as well as oil. Tianjin, Chongqing, Fujian and Hubei rely primarily on coal, which is the most polluting. Consequently, these four provinces receive a greater number of carbon emissions permits than do Beijing and Shenzhen.

\section{Eight Regional Markets in China}


In order to control global warming and climate change, China has taken some direct actions to control carbon dioxide emissions. One important measure has been to build a carbon trading system. Since China is a large county in terms of population, as well as geographically, economically, and financially, the manufacturing, capital flows, and financial markets are different in the various provinces, so it is difficult to develop a national market. The Central Government intends to develop a national market by starting from regional carbon markets. Provinces with large manufacturing sectors that consume significant fossil fuels and discharge substantial carbon dioxide, large capital and mature financial markets, are the ideal provinces to act as the first carbon markets. Guangdong, Shenzhen, Shanghai, Beijing and Tianjin meet these requirements. One reason for Beijing, Shanghai, Tianjin and Chongqing to be the pilot provinces is that they are four directly-controlled municipalities, led by the Central Government, and can execute policies of the Central Government more efficiently.

In 2011, China National Development and Reform Commission decided to create seven regional carbon trading markets, namely Shenzhen, Guangdong, Beijing, Shanghai, Tianjin, Hubei and Chongqing. In mid-2013, the first regional carbon market, the Shenzhen carbon market, was established. Subsequently, the Beijing, Shanghai, Guangdong, Tianjin, Hubei, Chongqing carbon markets were established. By 2017, the Fujian carbon market was established after the successful running of the seven regional markets. After several years of carbon emissions trading in the regional markets, China has recently become one of the largest carbon emissions trading countries internationally.

In the report of the China National Development and Reform Commission, by 2017 nearly 3000 companies had become involved in carbon emissions trading and carbon emissions reduction. About 197 million tons of carbon emissions, worth 4516 million RMB, had successfully been traded in the six regional markets.

Carbon markets in China differ in different provinces. The regulations of the eight regional markets are different, the companies in the eight regions are different, investors in the eight markets are different, with different trading frequencies, trading volumes, and trading prices. Since China is immense, different provinces have different economic development levels, so their carbon markets are unsurprisingly different. In order to understand Chinese markets, the different markets should be analyzed separately, and then compared against each other.

\subsection{Shenzhen}


Shenzhen is the earliest carbon market in China. According to the Shenzhen carbon emissions regulations ("a number of provisions of carbon emissions management of Shenzhen special economic zone”), companies that discharge more than 3000 tons of carbon dioxide per year, and buildings with Construction area greater 20,000 square metres, must participate in the Shenzhen carbon emissions control and carbon market trading.

Companies participating in the Shenzhen carbon emissions control are less polluted than companies in the other five provinces, and Shenzhen has been developing advanced manufacturing, which is less polluting. This is why the Shenzhen government set the participated requirement at 3000 tons of carbon emissions, where some markets are 20000 tons. These companies do not require excessive fossil fuels, which means that the requirements of carbon emissions of companies will be more stable than the requirements of heavy industry. As reflected in the price, Shenzhen carbon prices are more stable, with no extreme values.

The Shenzhen carbon market is independent of other carbon markets in China (which is the same as for the other seven markets) as carbon emissions traded in the other markets cannot be traded in Shenzhen. Carbon emissions traded in the Shenzhen market (SEA) cannot be traded in other markets, except for when China has certified voluntary emissions reductions (CCEA), which can substitute for regional carbon emissions partially. However, the substitution ratio of CCEA to regional carbon emissions is very low, usually less than $10 \%$.

Shenzhen has the most severe punishments for compliance failure. If companies fail to submit the emissions on time, it needs to pay a monetary penalty which is equal to three times the carbon price in the market. The companies will also be criticized by the appropriate authorities, be reported to credit management institutions, and also be reported to the Shenzhen Municipal Finance Department to cancel all their current and future financial aid for the following five years. The company emissions situation must attain third-party agency verification, where the qualification of the third-party agencies is checked by the regional government.

Both companies and investors can participate in Shenzhen carbon emissions trading. The different requirements for companies and investors are that companies participating in the Shenzhen carbon emissions trading must be companies that operate in Shenzhen. Moreover, Shenzhen is the only carbon market that is open to 
foreign investors.

According to the "Annual Report of Shenzhen Carbon Emissions Trading Scheme First-year Operation” (RSCEO), 37.5\% of Shenzhen carbon emissions in the first-year is discharged by manufacturing and building, $27.7 \%$ by transportation, 20\% by business, $17.4 \%$ by electricity power generation, with some overlap, and the rest by others.

By 2016, there were 900 companies participating in the carbon trading system in Shenzhen. Figure 3 shows that trade of SZHA is more frequent near the submission day, which means that main traders in SZHA are companies. However, there are some other high frequent trading periods, such as January 2016 and February 2017, which means that trading in SZHA is not only for compliance purposes, but also for investment.

The Shenzhen carbon market is the earliest running regional market in China. In May 2013, when the market was established, the carbon price was less than 30, and increased dramatically in the following few months, and once broke 100. However, at that time, the Shenzhen carbon trading volume was not big. With increased trading in SHEA, the price has decreased to around 40 .

\subsection{Guangdong}

According to the Guangdong Government regulations, compaies belonging to power generation, cement, steel, ceramics, petrochemical, textile, nonferrous metals, plastics, paper and other industrial sectors, and discharging 20,000 tons of carbon dioxide emissions per year (or integrated energy consumption of 10,000 tons of standard coal) or more, should take part in the carbon control and trading system.

Upon inauguration, carbon emissions permits were allocated to companies essentially for free (for example, 97\% in 2013 in Guangdong). When the market became established, companies had to pay for the carbon emissions quota. Guangdong is the first market to use open auction in the primary market: $3 \%$ of carbon permits in the primary market are allocated through auctions, mainly to the companies or institutional investors. This is an important step in the principle of "Paying for pollution”. By 2017, there were 246 companies in Guangdong that had been included in the carbon emissions control and trading policy. Guangdong is now the largest carbon emissions markets in China, based on trading volume and value. 
Guangdong is one of the most important regional carbon markets in China. According to the "China Carbon Market Analysis", (CCMA) in the primary market, 88.6\% of the volume of carbon permits traded by auction in the seven regional markets (not including Fujian) is in Guangdong, as well as the $94.83 \%$ of the turnover. In the secondary market, $25.98 \%$ of the accumulated volume of the seven markets is in Guangdong, which is the second largest after Hubei. In addition, 18.11\% of the accumulated turnover of the seven markets is in Guangdong, which is the third largest market after Hubei, Shenzhen and Shanghai. Moreover, the Guangdong market has been expanding the fastest. In 2016, Guangdong was the largest carbon market by volume, which accounted for $33.96 \%$ of the carbon permits of the seven markets, as well as the second largest market by turnover, which accounted for $25.85 \%$ of the seven markets, after Shenzhen.

Figure 4 indicates that the trading volume of Guangdong carbon emissions is concentrated on the submission day. The trading volume is dramatically larger in June 2015, June 2016 and June 2017 than usual. There is another trading peak in February 2017, and trading is more frequent in 2017, which indicates that an increasing number of companies and investors trade GDEA for investment.

According to the "Guangdong Carbon Market Comment and China Carbon Market Investment Analysis” (GCCCCIA), in 2013, 89.41\% of the carbon trading was for compliance purposes, the ratio decreasing to $69.91 \%$ in 2014, and $51.72 \%$ in 2015. One-half of carbon trading in 2015 was for investment. Foreign investors can also participate in the Guangdong carbon trading market. By June 2016, three foreign investors had participated in the Guangdong Carbon Market, with $10.74 \%$ of the carbon emissions in the second-hand market being traded by these three investors.

The Guangdong market tends to trade by negotiated transactions. According to "GCCCCIA", in 2013, 26.9\% of the carbon transactions were by negotiated transactions, with $73.1 \%$ in electricity bidding. Initially, participants were more willing to trade by electricity bidding, which is more open. As companies had no experience of trading carbon allowances with other companies, they preferred to trade by electricity bidding.

Subsequently, companies learned to trade with other companies. In 2014, 51\% of total transactions was by electricity bidding, and the negotiated transaction rate increased to $49 \%$. In 2015 , the electricity bidding transaction rate decreased to $33.6 \%$, and the 
negotiated transaction rate increased to $66.4 \%$. Participants tending to trade by agreement was mainly because most were companies. As the Guangdong carbon market is still relatively immature, prices in electricity bidding are not stable. A similar comment regarding instability also applies to supply and demand.

\subsection{Shanghai}

According to the Shanghai Government regulations, companies that discharge more than 10000 tons of carbon dioxide should be included in the carbon control and trading system. The participation requirement in Shanghai (which is 20000 tons) is higher than in Guangdong, but lower than in Shenzhen (which is 3000 tons). Companies in Shanghai are not as competitive as companies in Shenzhen regarding carbon emissions.

According to GCCCCIA, the Shanghai Carbon Market covers Industrial and non-industrial sectors. The industrial sector includes steel, petrochemical, chemical, non-ferrous metals, electricity, building materials, textiles, paper, rubber and chemical fiber. The non-industrial sector includes aviation, seaports, airports, railways, commerce, hotels and finance. There are 191 companies included in the Shanghai Carbon Market in 2013, the same as in 2014 and 2015.

The amount of carbon permits that the Shanghai Government allocated to companies is 1.6-1.7 billion tons each year from 2013 to 2015. As distinct from the other seven provinces, the Shanghai Government allocated companies three years of carbon permits in the initial years. As a result, an over-supply means that the Shanghai Carbon Market did not trade a lot in the first and second years of trading.

In the secondary market, Shanghai carbon emissions trading volumes were about 1973714 tons in 2014, 2940496 tons in 2015 and 12036181 tons in 2016. Shanghai carbon emissions trading volumes increased dramatically from 2014 to 2016, at around $500 \%$. The carbon trading value did not increase but decreased slightly during the period, which was 75492900 yuan in 201460908348 yuan in 2015 and 62812405 in 2016, primarily because the mean price of Shanghai carbon allowances decreased substantially. In 2014, the carbon spot mean price was 36.62 yuan, and declined to 20.33 yuan in 2015, and to 9.93 yuan per tons in 2016. The highest price was 44.91 yuan and the lowest price was 0.085 yuan per ton.

Figure 5 shows that Shanghai carbon emissions trading was also concentrated on the 
submission day before 2017, which indicates that Shanghai carbon emissions were traded mainly for compliance purposes at that time. In 2017, the carbon emissions trading became more frequent, with two trading peaks in 2017, one in March and the other in July. Similar to the Shenzhen and Guangdong markets, there were more and more investors participating in the Shanghai carbon emission trading market.

The change rate of Shanghai carbon permits in the secondary market was $0.97 \%$ in 2013, which increased to $1.67 \%$ in 2014 , and $7.55 \%$ in 2015 . The change rate increased fast during the first three years, which was 67\% in 2014 and $366.0 \%$ in 2015, which indicates that the Shanghai Carbon Market was becoming more liquidity.

By 2016, 335 companies in Shanghai had participated in the carbon control and trading system. Interestingly, the Shanghai market also has established carbon futures, where four carbon futures products have been traded in the Shanghai carbon market, including SHEAF022017, SHEAF052017, SHEAF082017 and SHEAF112017.

\subsection{Beijing}

According to the Beijing Government regulations, companies that consume more than 2000 tons of coal equivalents should be involved in the carbon emissions control and trading system. This regulation is similar to that in Guangdong.

Investors must be Beijing residents or overseas Chinese or foreigners who have been living in Beijing for more than two years, together with other conditions that investors must meet. There are many restrictions for investors to participate in the Beijing carbon trading market, which means that the Beijing carbon market is less influenced by other carbon or financial markets because of the barriers to entry.

Beijing Carbon emission trading volumes are about 1071505 tons in 2014, 1254586 tons in 2015 and 2473351 in 2016. The trading volume of Beijing carbon emissions is growing fast, almost increase $130 \%$ from 2014 to 2016. But the trading volume varies a lot, the minimum trading volume is zero, the highest trading volume is 154960.0 tons. The Beijing carbon trading value is about 63734508 yuan in 2014, 58571343 yuan in 2015 and 121000000 yuan in 2016. Among the period, the highest price is 77 yuan per ton and the lowest price is 31.8 yuan per ton.

From Figure 8, we can see that the percentage of Beijing carbon trading volume is become smaller and smaller from 2014 to 2016 and significantly smaller than the 
percentage of the Biggest Three Markets, Shenzhen, Guangdong and Shanghai. This is because the carbon emissions quota for Beijing is not as many as Guangdong and Shanghai and it is more difficult for investors to participate in the Beijing Carbon Emissions Market than the Biggest Three Markets.

Beijing market has the largest number of the company participants. But from Figure6, it indicates that Beijing carbon trading volume is only concentrate on the submission day, this is because there are many limitation for investor to participate in the Beijing Carbon Emission Market, and companies in Beijing is more polluted than companies in Shenzhen. Moreover, the carbon emissions quota for Beijing is almost the least among the six markets, so most of the carbon emissions were used to performance. As a result, the trading peaks of Beijing carbon emissions are only near the submission day, which is different from the Shenzhen, Guangdong and Shanghai markets.

\subsection{Tianjin}

According to the Tianjin Government regulations, companies belonging to the steel, chemical, power, heat, petrochemical, oil and gas exploration industries, and discharging more than 20000 tons of carbon dioxide, should participate in the carbon control and trading system.

The Tianjin carbon emissions trading volume was about 1011340 tons in 2014, and decreased to 975713.0 tons in 2015, and to 367936.0 tons in 2016. The Tianjin carbon emissions trading volume decreased 63.6\% from 2014 to 2016, which indicates that the Tianjin market has been shrinking. The Tianjin carbon allowance turnover also continued to decrease, from 20510762 yuan in 2014, 13950751 in 2015, and 3662109 in 2016.

The mean price of Tianjin carbon allowances continued to decrease from 2014 to 2016, namely 29.45 yuan per ton in 2014, which decreased to 22.93 yuan per ton in 2015, and to 20.89 yuan per ton in 2016. The highest price reached 50.11, and the lowest price was 24.62. It seems that the Tianjin market is shrinking, but the range of the Tianjin carbon allowance price changes is not as large as in Guangdong, Shenzhen and Shanghai.

Figure 9 shows that the percentage of Tianjin carbon emissions trading volume decreased from 2014 to 2016, which is similar to Beijing. The Tianjin carbon emissions trades were concentrated on the submission day, which is also similar to 
Beijing. The trade peak of the Tianjin carbon market is much higher, that is, in July 2014, 2015 and 2016. Most trades occurred in a single day, which is strange in financial markets. A trade peak occurred in April 2017, which may suggest that there is trading in TJEA for investment purposes. The high volume was also traded in a single day.

Tianjin carbon trading is too concentrated, with the price of TJEA not changing frequently. The TJEA price was virtually unchanged during October 2014- April 2015, August 2015- May 2016, and August 2016-March 2017.

\subsection{Chongqing}

According to the Chongqing Government regulations, companies that discharged more than 20000 tons of carbon dioxide must be involved in the carbon control and trading system. The Chongqing Carbon Market covers several industries, included electricity, metallurgy, chemicals, and building materials.

There are 242 companies included in the Chongqing Carbon Market in 2013, the same as in 2014 and 2015. The amount of carbon permits that the Chongqing Government allocated to companies was 1.25 billion tons in 2013. However, there were almost no trades in 2013, which means the carbon permits were over supplied. Therefore, the amount that the Chongqing Government allocated to companies decreased to 1.16 billion tons in 2014, which was excessive according to the market performance. As a result, the amount decreased to 1.06 billion tons in 2015.

The reason for the over-supply in Chongqing carbon allowances is ascribed to the allocation method. As distinct from the other seven markets, which were based on the historical pollution or standard methods, the Chongqing Government allocated the carbon permits in the primary market based on the applications from companies. Companies will always apply for a greater number of permits than are needed as it will assist them in avoiding penalties from the government due to emitting too much carbon dioxide. Simultaneously, companies can sell the extra permits in the market. As a result, almost all the compliance companies possess a greater number of permits than what is actually needed. If compliance companies do not need the permits, they have no investment value, so investor will not try to buy the permits.

There was only one trade in Chongqing carbon emissions allowances in 2014, with price at 30.74 yuan per ton, trading volume at 145000.0 tons, and turnover at 4457300 
yuan. The trading volume decreased to 24671.79 tons in 2015, and increased to 459951.0 tons in 2016. The trading turnover was 2335220 yuan is 2015, and 3665366 yuan in 2016. If we ignore the trade in 2014, which was an extreme value, the Chongqing carbon allowance trading volume and value continued to increase, with the highest price at 47.52 yuan and lowest price at 1.0 yuan per ton.

Compared with the Big Four markets, the Chongqing market traded CQEA very little. At initiation, there was almost no trading in CQEA, and only in late 2016 did trading of CQEA become active. Companies do not trade carbon allowance in the market, so investors cannot purchase carbon emissions from companies. With little supply and demand, the Chongqing carbon emissions price decreased from 30 to less than 10 yuan.

The Chongqing carbon price increased in early 2017. In the three years from 2014, some companies might consume all their emissions, so trading in Chongqing carbon emissions became active. In fact, nearly 200 of the trades recorded occurred after January 2017. According to GCCCCIA, the change rate of Chongqing Carbon Allowances was $0.12 \%$ in 2013, which was the lowest among the first seven markets. The rate decreased to $0.08 \%$ in 2014 , and to $0.06 \%$ in 2015 . Due to the extreme value in 2014, and the special distribution of Chongqing Carbon trading, the change rate cannot reflect the real underlying trading frequency of Chongqing carbon permits.

\subsection{Hubei}

Hubei carbon market was established in 2014. As a large manufacturing province in China, the carbon permits that Central Government of China allocated to Hubei was the largest of the eight provinces. The Hubei carbon market covers five industries, including iron and steel, petrochemical, cement, power, and paper.

In the primary market, the amount of carbon permits of Hubei in 2014 was 3.24 billion tons, which is dramatically larger than the permits in Chongqing, which was 1.16 billion tons, and the permits in Shanghai, which was 1.6 billion tons. The amount of carbon permits of Hubei in 2015 decreased to 2.81 billion tons. It seems that Hubei carbon permits are still declining, but still account for a large ratio of the total permits of the Big Eight.

In the secondary market, by 2016, Hubei was the largest carbon market by accumulated trade volume and by accumulated trade turnover, at 31.12\% and 30.65\% 
of the seven markets, respectively. However, the trade volume and turnover of Hubei did not increase substantially. In 2016, the amount of Hubei carbon permits was the second largest among the early seven carbon markets by volume, which is after Guangdong, as well as the fourth largest carbon markets by turnover, after Shenzhen, Guangdong and Beijing.

Trade by electricity bidding is superior in establishing a reasonable price compared with negotiated transactions. As distinct from the other seven markets, electricity bidding is a very important trading method for Hubei. According to the report of the Hubei Exchange, the Hubei accumulated carbon permits trading by electricity bidding was 51812 thousand tons, and the accumulated trading volume by electricity bidding was 9.99 billion yuan, which accounted for $27.8 \%$ of the eight regional total trading volume, and $30.4 \%$ of total trading turnover, respectively.

For a number of reasons, the Hubei exchange only published the data for nearly 180 trading days. Figure 9 shows that there are two volume peaks in April 2017 and June 2017. It seems that trading in Hubei carbon permits is not only for compliance purposes, but also for investment. The carbon price declined from 16 in April to 12 in August, then increased to about 14.5 in November 2017.

The participants of the other seven markets were mainly companies, but for Hubei, the main participants were private and institutional investors. By 2016, there were 6484 participants in the Hubei carbon trading system, with 167 compliance companies, 84 institutional investors, and 6233 private investors. More than 97\% of the participants are investors, which is dramatically higher than Shenzhen, Beijing and Shanghai, which had 58\%, $12.5 \%$ and $54.4 \%$, respectively. The amount of participants in the Hubei market was also the largest among the eight markets. The number of participants was around 2000 in Shenzhen, 1042 in Beijing, and 418 in Shanghai. This is an important reason why the Hubei accumulated carbon trading volumes and turnovers are significantly large among the Big Eight.

According to the report of the Hubei exchange, by November 2017, the accumulated carbon trading volume was 3.12 billion tons, and the accumulated turnover was 72.26 billion yuan, which indicates that the Hubei market is one of the most important regional carbon markets.

Interestingly, the Hubei market has some carbon derivatives. According to "GCCCCIA", the Hubei market launched futures on 27 April 2016, namely 
HBEA1705. The product had a trading volume of 6800 thousand tons, with a total value of 1.5 billion yuan on the first trading day. By June 2016, the accumulated trading volume of Hubei carbon futures were 2.43 billion tons, with a trading value of 24.26 billion yuan.

\subsection{Fujian}

The Fujian carbon market was established in late 2016 and commenced in early 2017, which was not in the first planned seven markets. Fujian carbon market covers nine industries, included electricity, petrochemical, chemical industries, building materials, steel, non-ferrous metals, paper, aviation and ceramics. Companies that discharge more than 10000 tons of carbon dioxides must participate in the carbon emissions control and trading.

Figure 10 shows that the Fujian carbon price floated up and down around thirty-five yuan from January to April, and then increased to thirty-five yuan each ton in July. Trading in Fujian carbon permits is concentrated in July, but there are also some trades in the months before June, which indicates that trading in Fujian carbon permits were mainly for compliance purposes.

\subsection{Comparison of Seven Regional Markets}

From Figure 11 and Table 4, we see that the five biggest markets, Guangdong, Shanghai, Shenzhen, Beijing and Hubei, trade around 96 percent of the total turnover, although this can change from 2014 through to 2017. From Figure 11, it is clear that Shenzhen and Hubei are the two largest markets for turnovers in 2014 and 2015. However, Guangdong joins the previous two provinces as being significant in 2016, while Shanghai joins the Big Four in 2017. Therefore, turnovers seem to be changing quite dramatically in a short span of 4 years, with the smaller three provinces in Beijing, Tianjin and Chongqing having relatively small impacts.

From Figure 12 and Table 5, which refer to volumes rather than turnovers, Hubei is clearly the largest in 2014 and 2015, followed by Guangdong in 2015. However, Guangdong dominates in 2016 and 2017, followed by Hubei in 2017. Just as in the case of turnovers discussed above, there can be dramatic differences over a short period of 4 years as to which provinces are dominant. It is also worth noting that Chongqing has come from being virtually invisible in the period 2014-2016 to dominate both Beijing and Tianjin in 2017. 
It means that most of the carbon emission trade occurs in five markets. One explanation is that the industry structure of the western area is different from the industry structure of the eastern area. Another explanation is that companies located in the west have not been supervised well. What is most likely is that investors do not want to participate in western markets. The eastern area has better regulations for companies and financial markets, better laws and regulations, more financial trading experience, greater liquidity, and better markets.

\section{Implementing a National Carbon Emissions Market}

The China National Development and Reform Commission has proposed establishing a national carbon market, which can attract more investors and companies to participate in carbon emissions trading. Sufficient liquidity will help to achieve a more reasonable price and make transactions more stable.

However, there are some obstacles in establishing a national market. First, the markets of the Big Four are much higher than for the others. If all the regions are required to pay the same price for carbon emissions permits, it will increase the production costs of companies in the mid-west as they will be facing higher carbon emissions costs.

Second, a national market will require that the carbon reduction ratio in the same industry in different regions should be the same. For an industry, no matter whether it is located in the mid-west or in the east, they must reduce carbon emissions by the same ratio. Generally speaking, companies located in the east own better technology, more capital, convenient transportation, benefits of more efficient government, and better market environment. The some reduction ratio will weaken the competitiveness of companies in the mid-west.

Despite the possible disadvantages of a national market, there are also some advantages in a national market. For the proposed national market, company belonging to some industries should participate in the carbon emissions control and trading system. As shown in Table 3, companies that belong to the petrochemical, chemical, building materials, steel, nonferrous metals, paper, electricity and aviation industries should participate in the national carbon emissions and trading system as these industries are the most energy-consuming and, hence, discharge a lot of carbon dioxide and need carbon emissions permits. 


\section{Supply of Carbon Emissions}

There are two kinds of carbon emissions permits. One is the regional carbon permit, while the other is the CCER. Regional carbon emissions have mainly been supplied by the Government until now, with $95-97 \%$ of the quota given to companies free of charge, with a company being able to use or trade them in carbon markets. With the development of carbon markets and a supervision system, the Government will increase carbon emissions (given to companies) prices from free to market prices. Investors can buy or sell carbon permits in the secondary market, which means that carbon emissions can be supplied directly by companies and also supplied indirectly by regional Governments.

Investors and companies can obtain carbon emission from the Government, but also the producers. Some companies can produce carbon quota, which is called CCER. The companies which are not required to participate in the carbon emission, such as hydro power projects, wind power projects, solar power and biomass power generation, are willing to join in carbon reduction. The amount they reduce can become the CCER. Forest management and forest plantation can also reduce carbon dioxide. The amounts these industry reduce the carbon dioxide become the CCER. CCER can partially substitute carbon emissions. But the allowed substitute ratio is different in the eight regional markets.

CCER is mainly traded in Shanghai and Guangdong. According to "GCCCCIA", in $201654.36 \%$ of the total CCER transactions occurred in Shanghai, followed by Guangdong at $21.94 \%$, with ratios of $12.16 \%$ for Beijing and $7.84 \%$ for Shenzhen. For Hubei, Tianjin and Chongqing, the CCER transactions were 1.73\%, 1.94\% and $0 \%$, respectively. CCER transactions are active in carbon markets while, in less active markets like Chongqing, CCER has almost no transactions. As CCER can only substitute the carbon permit partially, the price is lower. CCER is also traded mainly for compliance purpose, whereas, for investment, the regional carbon permits are more attractive because of higher prices and greater ease in selling.

\section{Carbon Pricing}

When regional governments give carbon permit to companies, it is virtually free (that is, $97 \%$ of the total). This means that, for the first market, most of the carbon emissions prices are zero but, when the companies sell carbon emissions in the second market, it is not free. Therefore, carbon emissions pricing is essentially concerned 
with the second market.

In the secondary market, there are two ways of conducting transactions, and hence two ways of determining carbon pricing, namely electricity biddings and negotiated transactions. Electricity biddings are like stock price, which is more open and reflects the true value of carbon emissions. Both companies and investors can trade carbon emissions by electricity biddings. Negotiated transactions occur between companies and companies. They can negotiate prices with each other. Generally, the price of negotiated transactions is based on the price of electricity biddings. However, it is easy for carbon emissions prices to deviate from their true value, and is easy to make markets include extreme values and increase the volatility of carbon prices because the owners of two companies may be related or have other connections.

In electricity biddings, there are three stages of carbon emissions spot pricing. The first stage is when the carbon market is established. The carbon spot price is decided by the Government, which decides the prices in Chinese regional markets by reference to Euro carbon futures prices and the demand and supply in regional markets. The second stage is mixed pricing, with government and market pricing working together. The third stage is market pricing, where the carbon price is decided solely by supply and demand.

The advantage of government pricing is to provide a price indication to companies. Government pricing usually cannot capture the real value of carbon. From Figures 3 to 8 , government pricing is too high for the market in Guangdong, Tianjin, and Chongqing. After these markets turn to market pricing, their carbon prices decline substantially. The Guangdong carbon price declines from an initial price of 60 to less than 20, the Tianjin carbon price declines from an initial price of 30 to less than 10, and the Chongqing carbon price declines from an initial price of 30 to close to zero.

For the Shenzhen and Shanghai markets, their carbon prices are reasonable close to their respective initial prices. However, Shenzhen and Shanghai carbon emissions prices have experienced large variations. For the Shenzhen market, government pricing is about 30, and increased to more than 120 in around six months, and decreased to 20 in October 2014, increased again, and then declined to nearly 30. For the Shanghai market, the government pricing is about 26, increased a little, and declined to 5, and then increased again and reached 30. It seems that government pricing in Shenzhen and Shanghai perform better than it does in Guangdong, Tianjin and Chongqing. 
For the Beijing market, government pricing seems to perform well as government pricing and market pricing are close, and Beijing carbon emissions prices do not experience large variations.

In short, regional carbon emissions prices are basically zero, and should increase to reasonable prices. Companies should pay for polluting. In the second market, carbon transactions should turn from a mixture of electricity biddings and negotiated transactions to electricity biddings, and from government pricing to market pricing.

\section{Lack of Liquidity}

Carbon markets still lack liquidity, according to data from the official website of the six regional markets. Most markets have almost 1000 trading days, while the Big Four have nearly 600 non-zero trading days. For the Tianjin and Chongqing markets, the observations are fewer. There are 461 non-zero trading days for the Tianjin market, and 215 non-zero trading days for the Chongqing market. These markets lack liquidity, which leads to higher fluctuations, so that more extreme values may occur.

From Figures 3 to 8, we can see that most of carbon emissions trading of the six regional markets concentrate on the submission day, which means that most of the emissions are traded for compliance purpose. Typically, there are few exchanges of carbon emissions in the six regional markets. For the Chongqing market, there are almost no trades on normal days, as only 200 of the 800 recorded days are not zero.

In order to measure liquidity, we can consider another index, namely the carbon exchange rate. According to GCCCCIA, the carbon exchange rate for Shenzhen was $33.13 \%$ in 2015, which is the highest of the eight regional markets, so that the traded carbon emissions are 33.13\% of total Shenzhen carbon permits in 2017. The second and third highest carbon exchange rate markets are Beijing and Guangdong, at 13.92\% and 8.26\%, respectively. The carbon exchange rate is lower in Beijing and Guangdong, but much lower in Shanghai, Hubei, Tianjin and Chongqing, at 7.55\%, 6.70\%, 0.83\% and $0.06 \%$, respectively.

In order to improve liquidity in carbon markets, we need carbon futures. The carbon spot price reflects the demand for carbon, but carbon futures may reflect improvements in reducing carbon emissions. It takes time for companies to improve and clean their products by reducing carbon emissions. Carbon emissions futures can 
reflect the willingness to reduce carbon emissions. Moreover, companies can reduce their lack of carbon emissions permit risk by buying futures, and investors can reduce their investment risk by adding carbon futures to their investment portfolios.

\section{Carbon Emissions Data}

Of the eight regional carbon markets, Shenzhen is the earliest, which was established in mid-2013. Shenzhen has the largest number of observations at 1040. From Table 8, the data for Guangdong, Shanghai and Beijing are from late-2013, and these markets have around 696, 601 and 644 non-zero observations, respectively. The Tianjin market started in late-2013, but there are fewer trades in Tianjin than in Guangdong, Beijing and Shanghai, and Tianjin has 461 non-zero observations. The Hubei carbon market was also established in late-2013. However, the Hubei Exchange only publishes data for several months, and there are only 79 non-zero observations for Hubei, so is not useful for econometric analysis. Due to an over-supply of Chongqing carbon emissions in 2014, there were almost no trade before 2017, so that Chongqing has about 200 non-zero observations. As a newly established market, Fujian has about 125 non-zero observations, including carbon prices, volumes and turnovers.

Due to the lack of data, we can compare the seven carbon markets. From Figure 12, the Guangdong market is the largest of the seven, and its percentage has been growing over time. Hubei, Shenzhen and Shanghai occupy important positions as the most important carbon markets in China. These three provinces not only have good manufacturing, but also possess better financial markets. Beijing also has large manufacturing, but due to limitations in participating in the Beijing market and a low supply of emissions, it is not as important as Hubei, Guangdong, Shenzhen and Shanghai. Tianjin and Chongqing are small, with few trades occurring in the two markets.

Figure 11 and Table 4 also indicate that in 2014, the biggest carbon market of the seven provinces is Shenzhen at $41.5 \%$, followed by Hubei at $24.5 \%$. In 2015 , the top two positions were reversed, with Hubei at 39.2\% and Shenzhen at 32.7\%. The leading two positions in 2016 were taken by Shenzhen at 30.7\% and Guangdong at 29.4\%. Finally, in 2017, Shenzhen, Guangdong, Shanghai and Hubei were very close at $23.1 \%, 21.9 \%, 21.3 \%$ and $19.2 \%$, respectively.

From Figures 3 to 10, the carbon prices are too high at the beginning, except for Shenzhen. When the government allows the market to decide prices, carbon prices 
decline. Most of the trades occur before the submission day in the six markets. For Guangdong, Shenzhen and Shanghai, there are also many trades occurring on the non-submission day, which means that some investors and companies trade carbon emissions permits as a financial investment.

\section{Data Availability}

As China has the one of the largest manufacturing industries in the world, it is to be expected that the China National Carbon market will also be correspondingly large. The size issue will be important in economics, finance, environment issues, and academic studies. The availability and access to the China carbon market prices and related data are crucial for investment analysis and academic investigation. However, China still has far to go in terms of data disclosure. As a result, it is necessary to discuss the data availability of China carbon markets.

Generally speaking, there are two sources of data from the China regional carbon markets. The first arises from primary data sources, which are published in the regional carbon exchange official websites, such as China Guangzhou Carbon Exchange and China Hubei Emission Exchange. The other source is secondary data source, as provided by some investment agencies or consulting agencies, such as "tanjiaoyi.com”. Basically, the secondary data is a derivative of the primary data sources.

The primary data is more reliable, while the secondary data tends to be more convenient for investment or research purposes, but is less reliable because it is processed by and through the investment or consulting agencies. For some data, we can only download from the secondary data sources because some data may only be offered to paid members. As an example, for Hubei carbon spot prices, visitors can only download the data in recent months. For academics purposes, the primary data sources should be used wherever possible as they are more reliable than the secondary sources.

It is also possible to obtain some processed data through reports provided by the regional carbon exchanges, such as the "China Carbon Market Analysis", “Guangdong Carbon Market Comment and China Carbon Market Investment Analysis”, and "Annual Report on Shenzhen Emissions Trading Scheme First-Year Operation". These reports sometime contain data which are not available directly through primary data sources, such as the exchange rate of regional carbon permits 
and members of covered companies in different provinces. The information contained in these reports are important in analyzing Chinese carbon emissions.

Primary data of the China energy consumption structure, regional energy consumption structure, GDP structure, and so on, can be found on the official websites of the China National Bureau of Statistic and Regional Bureau of Statistic.

Most of these data sources are available only in Chinese. Due to certain special national conditions, it is not easy for non-Chinese to understand some of the data and policies. It would be a better choice for China's Central government and regional governments to offer English copies of these document and data, but to date they have not been made available other than in Chinese.

\subsection{Limitations of provincial and national carbon pricing policies}

As mentioned above, there are limitations in China's carbon pricing policies, both in the primary and secondary markets. In the primary markets, carbon allowances are allocated to companies essentially gratis. According to "CCMA", the accumulated volume of carbon permits traded by open auction has been 18240 thousand tons, with 88.6\% having been traded in Guangdong, followed by Hubei, Shenzhen and Shanghai, which accounted for $10.97 \%, 0.38 \%$ and $0.05 \%$, respectively. There are no carbon permits traded by open auction in Beijing, Tianjin or Chongqing.

Most of the allowances traded by open auction have occurred in Guangdong, at 16161 thousand tons, but these carbon allowances accounted for less than $5 \%$ of the total allowances of Guangdong in the primary markets. It seems that the pricing policies in the primary markets of the seven provinces are essentially free, which is against the prevailing understanding that "Companies have paid for their right to pollute”.

Allocating carbon allowances for free can also help China to achieve target emissions, which is a significant step for China. Companies must product a strong base for determining the allocation of allowances, and to pay for additional polluting rights. For companies that have surplus carbon allowances, these can be sold. Therefore, companies can still polluted and obtain interest simultaneously by polluting less than other companies However, it does not seem to be a balanced scenario for society if the government allocates carbon allowances to companies without charge as carbon allowances are essentially a financial commodity, where associated costs should be borne in mind. 
There is an obvious advantage in allocating carbon allowances for free. If companies need to pay for the emissions immediately, they will have little time in promoting their clean product capabilities. As a result, company costs will increase, the price of the associated products will increase, thereby making the brand "Made in China" less attractive. China is essentially a manufacturing country, so reducing carbon emissions by impacting the manufacturing industry is far from optimal. Providing carbon allowances without payment may be a sensible strategy, but the government will eventually have to increase prices in the primary market in order to determine appropriate market prices for carbon emissions.

The secondary market essentially shifts from government pricing to market pricing. Government pricing makes carbon allowances a traditional tax, As the tax rate is decided by the government, without recourse to the underlying market conditions, it is unlikely to be optimal. Market pricing makes carbon allowances an optimal tax as the tax rate is decided by the market. From the Guangdong market, which is one of the largest, it is clear that government pricing is much higher than market pricing, which suggests that a lower tax rate can assist in achieving target emissions more efficiently.

Similar situations arose in Tianjin, Hubei and Chongqing. Market pricing is a superior meth for establishing national target emissions, and simultaneously stabilizing the economy. For purposes of developing and understanding a National Market that is presently under construction, turning to market pricing would seem to be a more sensible and efficient approach than imposing prices through administrative processes that do not reflect prevailing market conditions.

In the secondary market, there are methods of conducting transactions, namely electricity bidding and through negotiated transactions. The prices arising from these two transactions methods need not be similar. Generally speaking, these two methods are both market pricing methods. However, due to issues such as holding each other, belonging to the same parent companies, or both are national companies, negotiated transactions may not perform as well as electricity bidding for purposes in determining carbon emissions prices. In order to make the market mechanism work more efficiently, the government should reduce negotiated transactions and allow greater electricity bidding for purposes of achieving negotiated transactions.

However, electricity bidding requires adequate market liquidity. Pricing policies are not necessarily independent of other policies, such as submission policies. Carbon 
market liquidity depend on supply and demand. The supply of carbon allowances is not directly dependent on the primary market, but rather the secondary market, which determines just how many carbon allowances companies are willing to sell. In order to fulfill compliance and avoid punishment, companies tend to retain allowances for what might be interpreted as "insurance” purposes.

Companies tend to sell their allowances when they are confident that they have more than enough for compliance purposes, which is generally close to the submission day. As a result, the supply of allowances increases substantially near the submission day. As a result, a phenomenon that occurs around two months before the submission day is that carbon transactions increase but the price decreases. In such a scenario, electricity bidding may not work as intended.

\subsection{Availability of data at the provincial and national levels}

China's carbon emissions market presently operates at the provincial level as the national carbon emissions market is still under construction. For this reason, the data of carbon allowances data can be collected only for the eight regional markets.

Shenzhen was the earliest and most open regional market, having commenced in mid-2013. Information on Shenzhen carbon allowances are published on the official website of the Shenzhen Carbon Exchange, included daily prices, trading volume, trading value, and opening and closing prices. The information of CCER traded in Shenzhen can also be found on the website, as well as the Shenzhen carbon market regulations and some national carbon regulations, which is not available in all regional markets.

The Shenzhen Carbon Exchange provides some reports about the performance of the provincial carbon market, in addition to data available in other provinces. In fact, more than 3000 observations for five carbon products, namely SEA-2013, SEA-2014, SEA-2015, SEA-2016 and SEA 2017, are available. In this sense, Shenzhen is one of the most informative regional markets in terms of providing data on more than its own province.

Guangdong is one of the most important regional markets on the basis of trading volumes, established times, or the earliest experiment of trading carbon allowances by open auction in the primary market. Information about the Guangdong market is published on the official website of the Guangdong Carbon Exchange. Daily carbon 
price data, trading volume, turnover, and opening and closing prices, are available on the official website, which has almost 697 observations. Similar to the Shenzhen market, the information of CCER trading in Guangdong is published on the website, as well as the documents relating to Guangdong carbon regulations.

For the Shanghai carbon market, daily data of carbon price, trading volume and turnover are published on the official website of the Shanghai Environment and Energy Exchange, which has about 830 observations, but the opening and closing prices are not available. As the Shanghai market has carbon futures, a link to the Shanghai Clearing House, which provides related information, is available. Information on CCER trading in Shanghai, and documents of the Shanghai carbon emission regulations, are also available on the website. The Shanghai Environment and Energy Exchange also provides weekly reports on the Shanghai carbon market and other regional markets, which may contain useful information, such as newly covered entities.

The official website of the Beijing Environment Exchange provides daily Beijing carbon price data, trading volume and turnover, with more than 640 observations, but the opening and closing prices are not available. As distinct from the markets discussed above, the Beijing market only provides non-zero observations. Spot prices, trading volume and turnover of CCER trading in Beijing are also available on the official website, as well as documents relating to Beijing carbon regulations.

The Tianjin market is similar to Beijing as only non-zero observations of daily prices, trading volume and turnover are available. Moreover, the Tianjin market provides information on carbon allowances that are traded through negotiation, and not only the total trading volume and turnover. Information about CCER traded in Hubei and documents relating to Hubei carbon market regulations are also available.

Hubei is one of the largest markets, with significant accumulated trading volume and turnover. However, the Hubei Emission Exchange is parsimonious in terms of data disclosure. Only 200 daily data observations on carbon prices, highest and lowest prices, trading volume and turnover are available on the official website. As a result, it is essential to use secondary data sources, which have more than 1000 observations, in conducting research. The Hubei Emission Exchange provides data on CCER that is traded in all regional markets, as well as the daily Hubei carbon future prices, trading volume and turnover. However, as in the case for spot, only around 200 observations are actually made available. In short, the data exist, but are not necessarily made 
available.

For the Chongqing market, around 1000 observations on daily prices, trading volume and turnover are published on the official website of the Chongqing Carbon Emission Center. Of the 1000 observations, there are fewer than 300 that are non-zero. As CCER is not traded in Chongqing, there is little information about CCER available on the website, although documents relating to the Chongqing carbon regulations are available.

Apart from the above regional primary data sources, the China National Development and Reform Commission also provides information about China's national market, such as the industries that are covered, trading regulations, permit allocation methods for the different covered industries. As the national carbon emission pricing market is still under construction, only the power generation industry is involved.

Some secondary data sources provide data relating to the eight regional carbon markets, such as the Hong Kong Emissions Exchange. General speaking, the data disclosure of China carbon allowances is not adequate, and data on relevant variables are not easy to find, such as the complete daily Hubei spot prices. Morever, much of the available data is published in Chinese, which makes accessibility difficult for foreign investors and researchers.

\subsection{Similarities and dissimilarities of provincial data}

As mentioned above, there are different situations in different provinces, so the eight different regional markets have similarities and dissimilarities across the provinces.

For all regional markets, it is possible to obtain daily price data, trading volume and turnover. The prices in the eight markets are all average prices, which is turnover relative to volume. The trading volume includes allowances traded by electricity bidding and negotiation. Therefore, the average price is not the average price of electricity bidding, but a weighted average of electricity bidding and negotiated transactions.

There are some dissimilarities in provincial data. The first is the duration of the data. Shenzhen was the first regional market, having started in mid-2013, so it has the largest source of data, with more than 1000 observations. The inauguration of the Guangdong, Beijing, Tianjin and Shanghai markets are also similar, but the duration 
of their respective data are different. Specifically, Guangdong has about 700 non-zero observations, followed by Beijing and Shanghai, which have around 650 and 600 non-observations, respectively.

There are around 450 non-observations for Tianjin, which is significantly less than for Guangdong, Beijing and Shanghai. The Hubei and Chongqing markets commenced at similar times, but the duration of their respective data sets is dramatically different. Hubei has about 900 non-observations, which is fewer than Shenzhen, but Chongqing has only about 200 non-zero observations. The differences in the respective durations arise mainly because of different performances in the eight markets.

The variables that are available in the eight markets are different. For some markets, we can only obtain prices, trading volume and turnover, such as in Beijing and Chongqing. For some markets, we can also obtain the opening and closing prices, such as in Shenzhen and Guangdong. Tianjin provides the structure of the trading volume, so we can separate the negotiated transactions from the trading volume. For a market like Hubei, we can obtain the regional carbon prices, but also the CCER price, trading volume and turnover. Moreover, Hubei also provides daily data for Hubei futures, which is unusual for carbon markets in China. Although Hubei does not provide the complete daily data series for the whole sample period, it nevertheless provides more data than do the other provinces.

Some markets provide reports of regional market performance, and usually provide more than just price data, such as trading volume and turnover. These reports may provide the structure of participants, number of covered entities, percentages of volume, and turnover trade by companies, private investors and corporate investors in the primary and secondary markets. Such information may be useful in trying to analyze China's carbon markets.

The Shenzhen market provides the "Annual Report on Shenzhen Emissions Trading Scheme First-Year Operation", the Guangdong market provides the "Guangdong Carbon Market Comment and China Carbon Market Investment Analysis”, the Shanghai market provides some weekly reports of the provincial carbon market, and Hubei also provides some monthly reports of provincial carbon markets.

In short, China's carbon markets are have been developing very fast recently, and the China national carbon market is also under construction. It is meaningful and helpful to introduce and analyze China's regional carbon emissions markets and their pricing 
policies, and to try to provide some suggestions regarding an appropriate pricing model and policies for China's national market that is presently under construction.

\section{Concluding Remarks}

The purpose of the paper was to provide a clear mechanism for determining carbon emissions pricing in China as a guide to how carbon emissions might be mitigated to reduce fossil fuel pollution in China and in the international community. The Government of mainland China has promoted the development of clean energy, including hydroelectric power, wind power, and solar energy generation. In order to involve companies in carbon emissions control, a series of regional and provincial carbon markets have been established since 2013.

This paper provided an introduction to China's regional and provincial carbon markets, proposed how to establish a national market for pricing carbon emissions, discussed how and when these markets might be established, how they might perform, and the subsequent prices for China's regional and national carbon markets. In order to understand the regional markets well, it is necessary to analyze the energy structure in these regions. Coal is the primary energy source in China, so that provinces that rely heavily on coal receive a greater number of carbon emissions permits from the Government.

In order to establish a national carbon market for China, a detailed analysis of the eight regional markets was presented. The four largest energy markets, namely Guangdong, Shanghai, Shenzhen and Beijing, traded more than 98\% of the total volume and more than $99 \%$ of the total value of the six markets in 2016, as the industry structure of the mid-western area is different from that of the eastern area. The China National Development and Reform Commission has proposed the development of a national carbon market, which can attract investors and companies to participate in carbon emissions trading. This important issue was investigated in the paper.

A serious underlying concern in evaluating how to develop a national carbon emissions pricing scheme at the national level, using eight major provincial markets as a foundation, is that much daily data exist, but are not necessarily made available for analysis. There is little explanation available for this imbroglio, apart from administrative differences across the different provinces for a variety of reasons. Regulations will need to be modified and updated if a scheme that is based on 
provincial markets is to succeed as an optimal method of pricing carbon emissions at the national level. 
Table 1

China's Energy Consumption Structure (\%)

\begin{tabular}{|c|c|}
\hline Energy & \% \\
\hline Coal & 63.7 \\
\hline Oil & 18.3 \\
\hline Natural gas & 5.9 \\
\hline Nuclear power, Hydro, Wind & 12.1 \\
\hline
\end{tabular}


Table 2

Energy Consumption Structures for Six Regions (\%)

\begin{tabular}{|c|c|c|c|c|}
\hline Region & Coal & Oil & Gas & $\begin{array}{c}\text { Electricity } \\
\text { and others }\end{array}$ \\
\hline Guangdong & 42.3 & 27.3 & 6.4 & 24.0 \\
\hline Beijing & 13.7 & 33.5 & 29.0 & 23.8 \\
\hline Shanghai & 36.4 & 34.9 & 10.0 & 18.6 \\
\hline Shenzhen & 25.3 & 2.8 & 32.7 & 39.3 \\
\hline Tianjin & 50.0 & 28.0 & 9.3 & 12.7 \\
\hline Chongqing & 57.7 & 14.6 & 14.4 & 13.3 \\
\hline Hubei & 63.3 & 18.0 & 3.0 & 15.7 \\
\hline Fujian & 50.5 & 24.6 & 5.0 & 19.9 \\
\hline
\end{tabular}


Table 3

Industries Involved in National Carbon Markets

\begin{tabular}{|l|c|}
\hline Industry & Type of Company \\
\hline Petrochemical & Crude oil processing, Ethylene \\
\hline Chemical industry & Calcium carbide, Synthetic ammonia, Methanol \\
\hline Building materials & Cement clinker, Plate glass \\
\hline Steel & Crude steel \\
\hline Nonferrous metals & Electrolytic aluminum, Copper smelting \\
\hline Paper industry & Pulp manufacturing, Machine paper and cardboard \\
\hline Electricity & Pulp manufacturing, Machine paper and cardboard \\
\hline Aviation & Air passenger transport, Air cargo transport, Airport \\
\hline
\end{tabular}


Table 4

Turnovers in Seven Markets (\%), 2014-2017

\begin{tabular}{|c|c|c|c|c|}
\hline Markets & $\mathbf{2 0 1 4}$ & $\mathbf{2 0 1 5}$ & $\mathbf{2 0 1 6}$ & $\mathbf{2 0 1 7}$ \\
\hline Beijing & 9.4 & 6.6 & 12.8 & 11.2 \\
\hline Guangdong & 9.7 & 12.8 & 29.4 & 21.9 \\
\hline Shanghai & 11.1 & 6.8 & 6.6 & 21.3 \\
\hline Shenzhen & 41.5 & 32.7 & 30.7 & 23.1 \\
\hline Hubei & 24.5 & 39.2 & 19.8 & 19.2 \\
\hline Tianjin & 3.0 & 1.6 & 0.4 & 1.9 \\
\hline Chongqing & 0.7 & 0.3 & 0.4 & 1.5 \\
\hline
\end{tabular}


Table 5

Volumes in Seven Markets (\%), 2014-2017

\begin{tabular}{|c|c|c|c|c|}
\hline Markets & $\mathbf{2 0 1 4}$ & $\mathbf{2 0 1 5}$ & $\mathbf{2 0 1 6}$ & $\mathbf{2 0 1 7}$ \\
\hline Beijing & 6.6 & 4.1 & 4.2 & 3.7 \\
\hline Guangdong & 7.8 & 22.7 & 37.5 & 26.9 \\
\hline Shanghai & 12.1 & 9.6 & 20.2 & 15.2 \\
\hline Shenzhen & 11.2 & 14.4 & 18.1 & 16.5 \\
\hline Hubei & 55.2 & 45.6 & 18.7 & 22.8 \\
\hline Tianjin & 6.2 & 3.2 & 0.6 & 3.6 \\
\hline Chongqing & 0.9 & 0.4 & 0.8 & 11.4 \\
\hline
\end{tabular}


Table 6

Regional Markets and Sample Periods

\begin{tabular}{|c|c|}
\hline Markets & Sample Periods \\
\hline Beijing & $2013-11-28$ \\
\hline Shanghai & $2013-11-26$ \\
\hline Guangdong & $2013-12-13$ \\
\hline Shenzhen & $2013-06-18$ \\
\hline Tianjin & $2013-12-26$ \\
\hline Hubei & $2017-04-14$ \\
\hline Chongqing & $2014-06-19$ \\
\hline Fujian & $2017-01-24$ \\
\hline
\end{tabular}


Table 7

China's Carbon Emissions Allowance

\begin{tabular}{|c|c|}
\hline Product & Introduction \\
\hline BEA & Beijing \\
\hline GDEA & Guangdong \\
\hline HBEA & Hubei \\
\hline SEA & Shanghai \\
\hline SHA & Shenzhen \\
\hline TJEA & Tianjin \\
\hline CQEA & Chongqing \\
\hline FJEA & Fujian \\
\hline CCER & Chinese \\
\hline
\end{tabular}


Table 8

Shenzhen's Carbon Emissions Allowance

\begin{tabular}{|c|c|}
\hline Product & Year \\
\hline SZA-2013 & 2013 \\
\hline SZA-2014 & 2014 \\
\hline SZA-2015 & 2015 \\
\hline SZA-2016 & 2016 \\
\hline SZA-2017 & 2017 \\
\hline
\end{tabular}


Table 9

Non-zero Observations for Eight Markets

\begin{tabular}{|c|c|c|c|c|}
\hline Markets & Period & $\begin{array}{c}\text { Total } \\
\text { Observations }\end{array}$ & $\begin{array}{c}\text { Zero } \\
\text { Observations }\end{array}$ & $\begin{array}{c}\text { Non-zero } \\
\text { Observations }\end{array}$ \\
\hline Beijing & $2013-11-28$ & 644 & 0 & 644 \\
\hline Shanghai & $2013-11-26$ & 832 & 231 & 601 \\
\hline Guangdong & $2013-12-13$ & 697 & 1 & 696 \\
\hline Shenzhen & $2013-06-18$ & 1040 & 63 & 977 \\
\hline Tianjin & $2013-12-26$ & 461 & 0 & 461 \\
\hline Chongqing & $2014-06-19$ & 826 & 611 & 215 \\
\hline Hubei & $2017-04-14$ & 86 & 7 & 79 \\
\hline Fujian & $2017-01-24$ & 127 & 2 & 125 \\
\hline
\end{tabular}


Figure 1

China's Coal and Gas Production

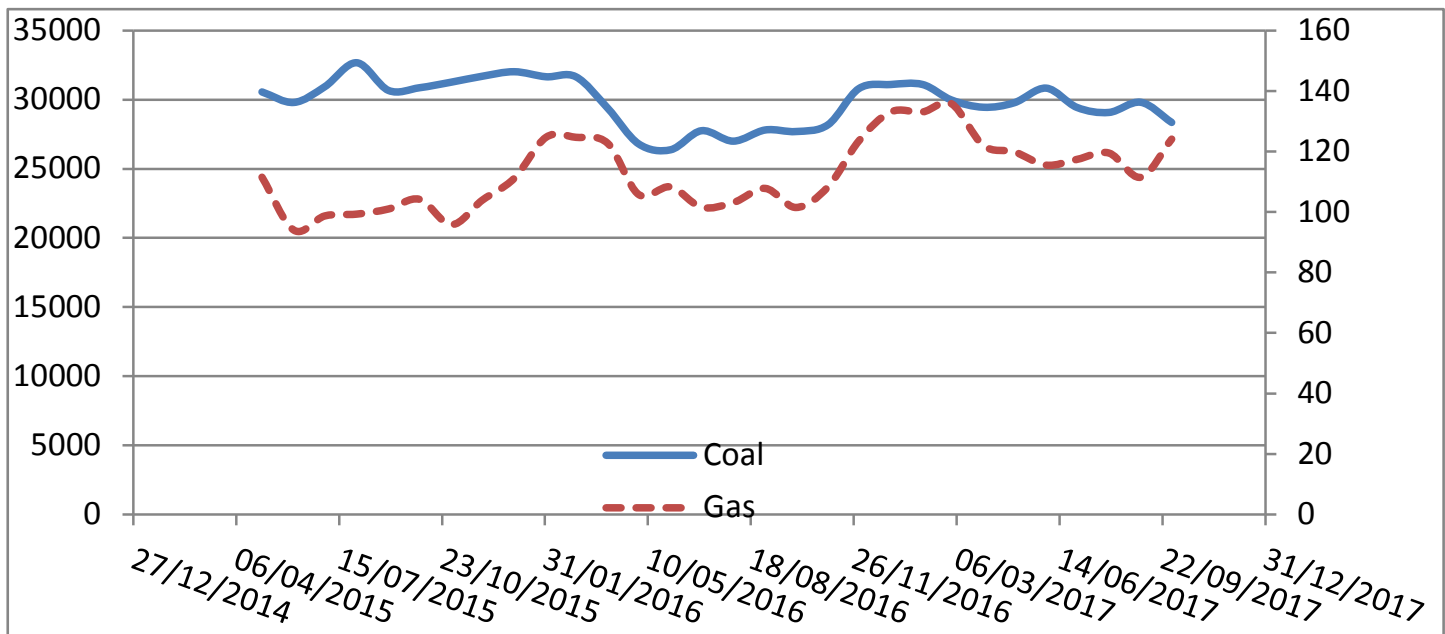


Figure 2

\section{China's Oil Imports and Import Ratio}

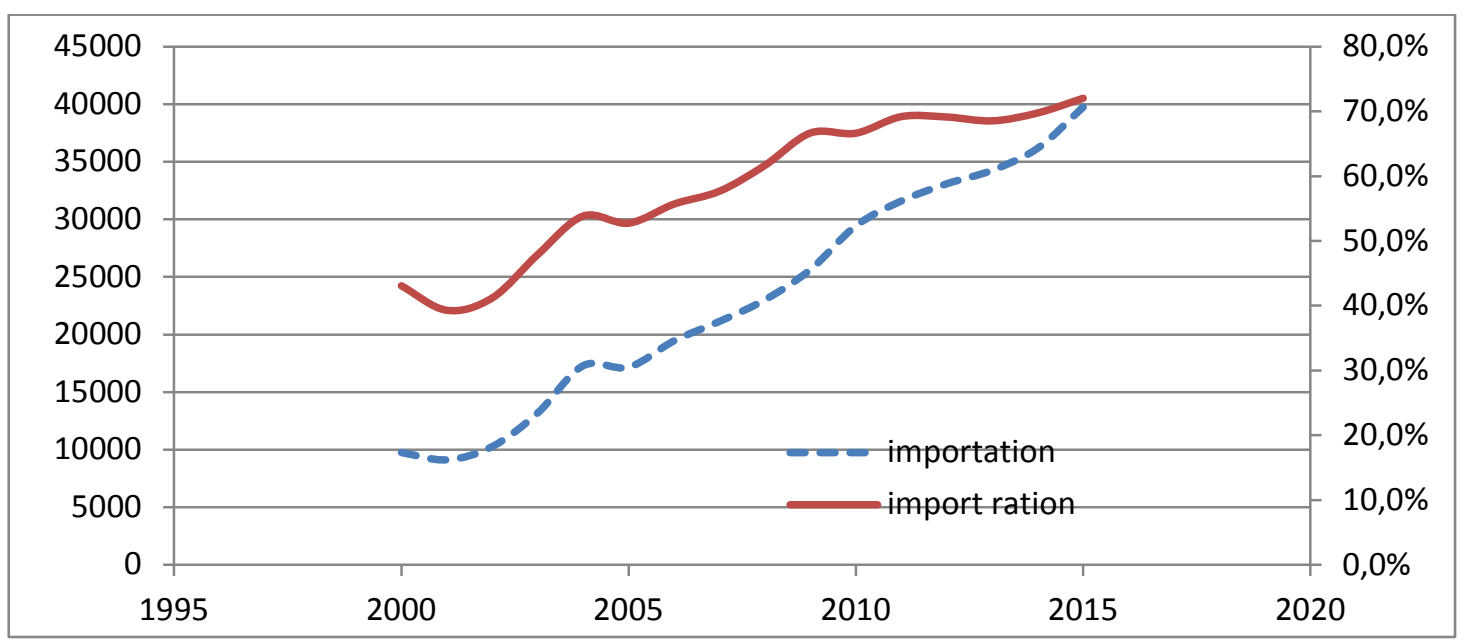

Note: The import ratio is the ratio of imports to the total consumption of oil. 
Figure 3

Shenzhen's Carbon Spot Price and Volume

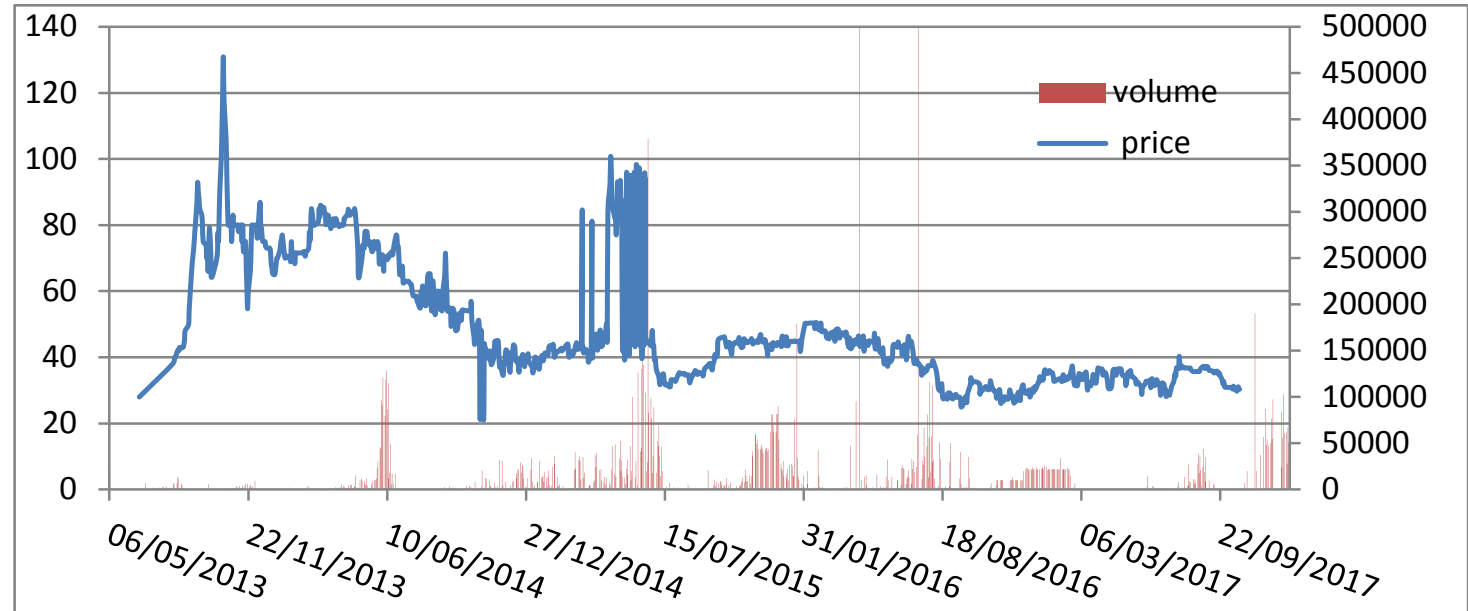


Figure 4

Guangdong's Carbon Spot Price and Volume

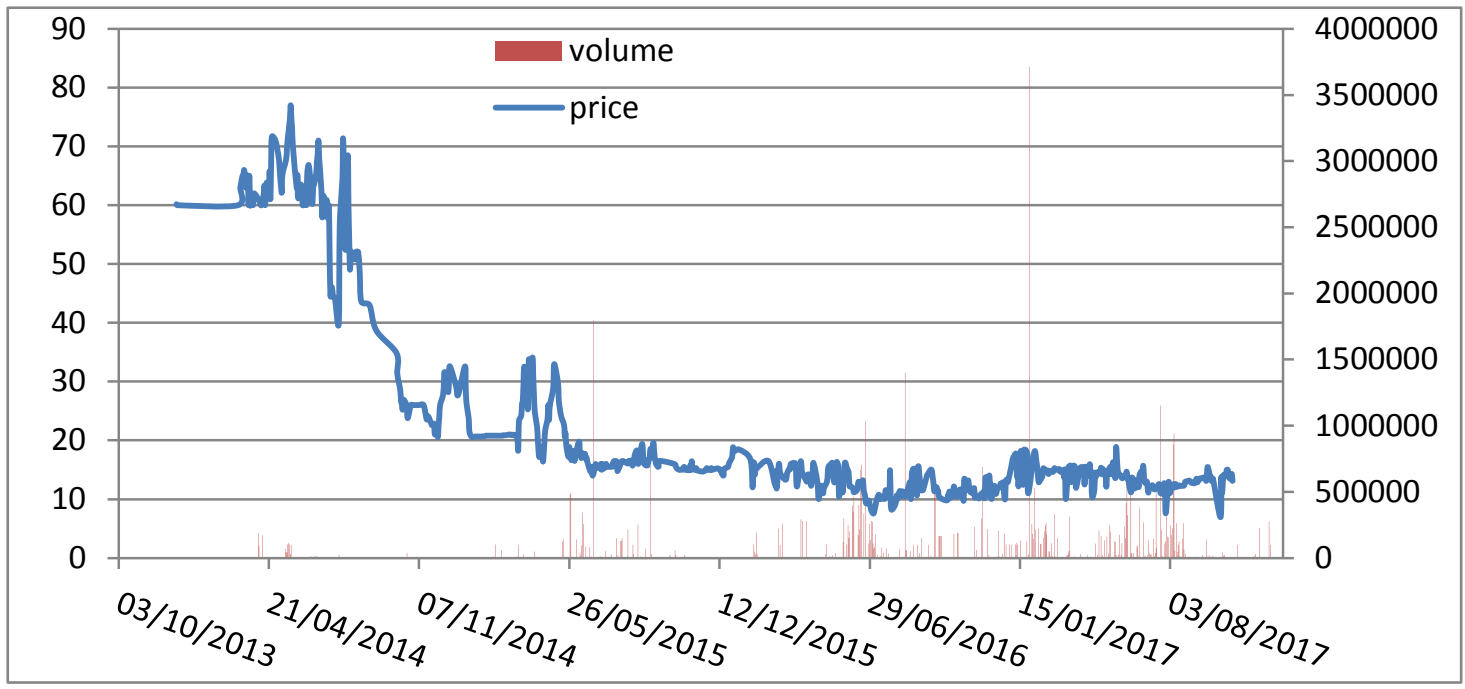


Figure 5

Shanghai's Carbon Spot Price and Volume

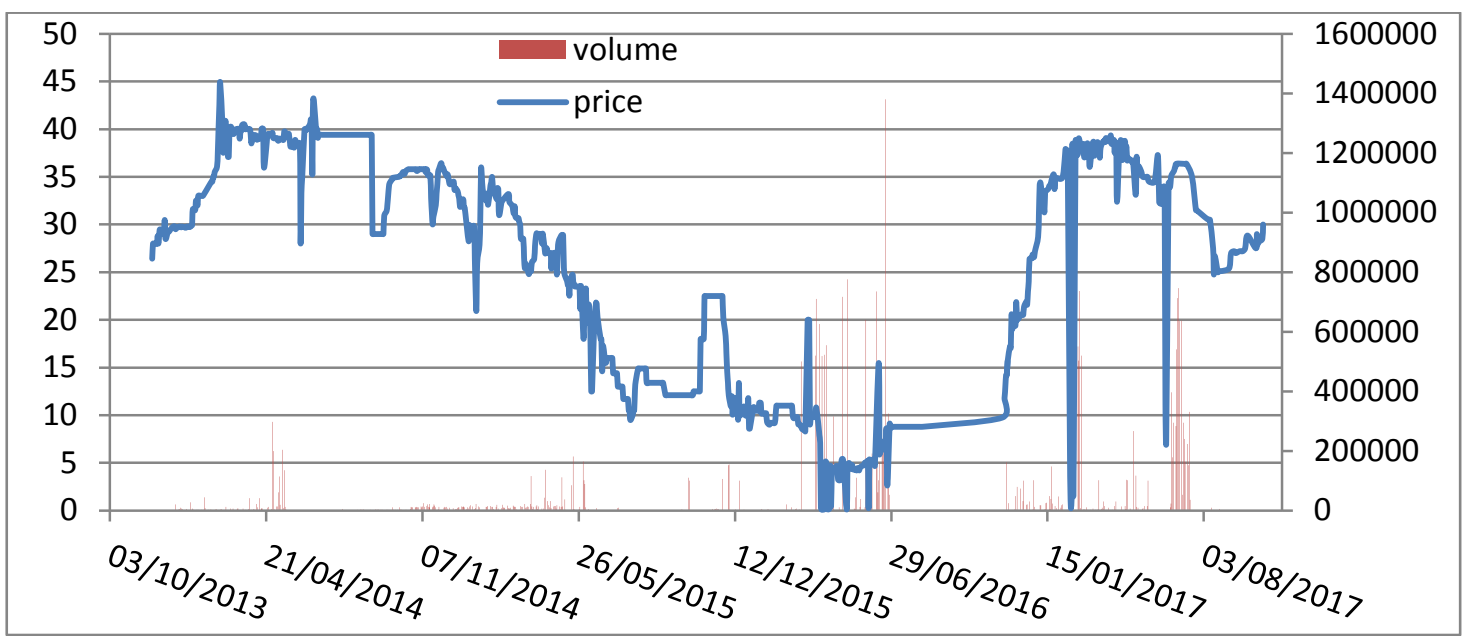


Figure 6

Beijing's Carbon Spot Price and Volume

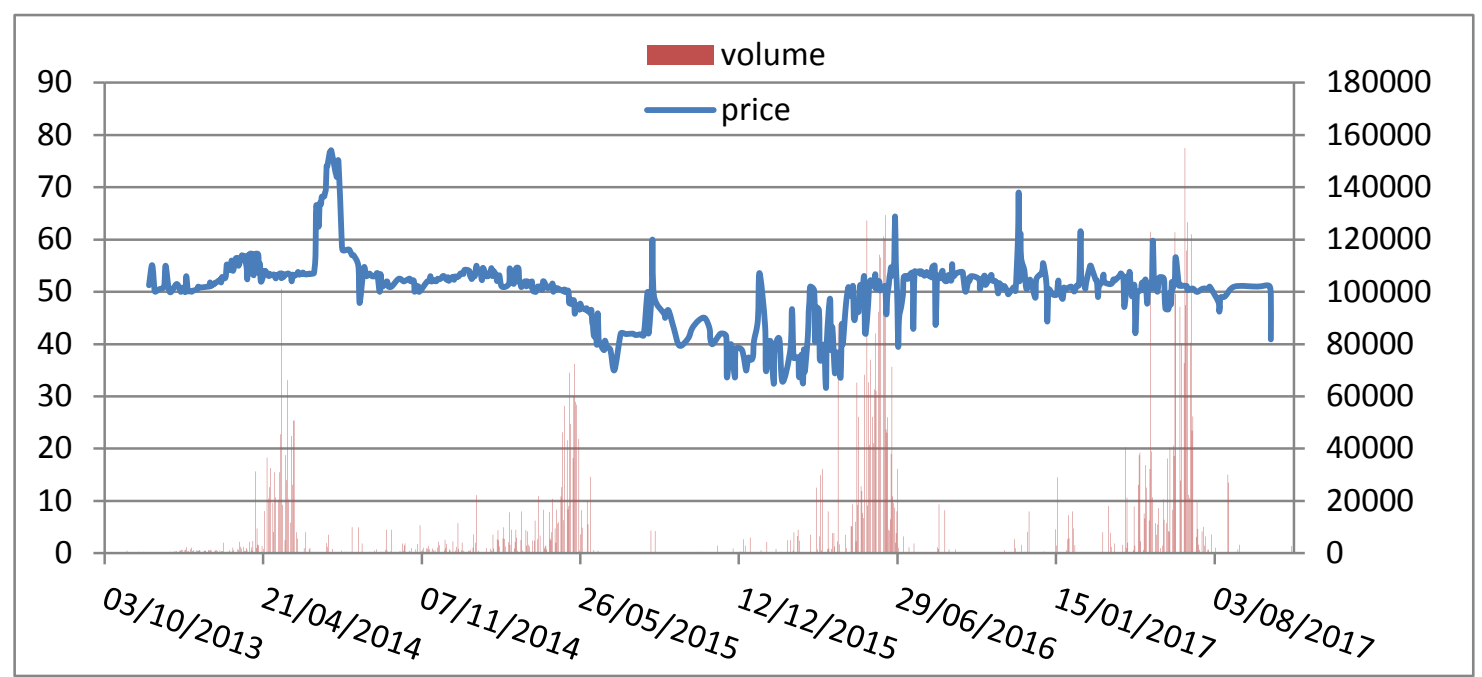


Figure 7

Tianjin's Carbon Spot Price and Volume

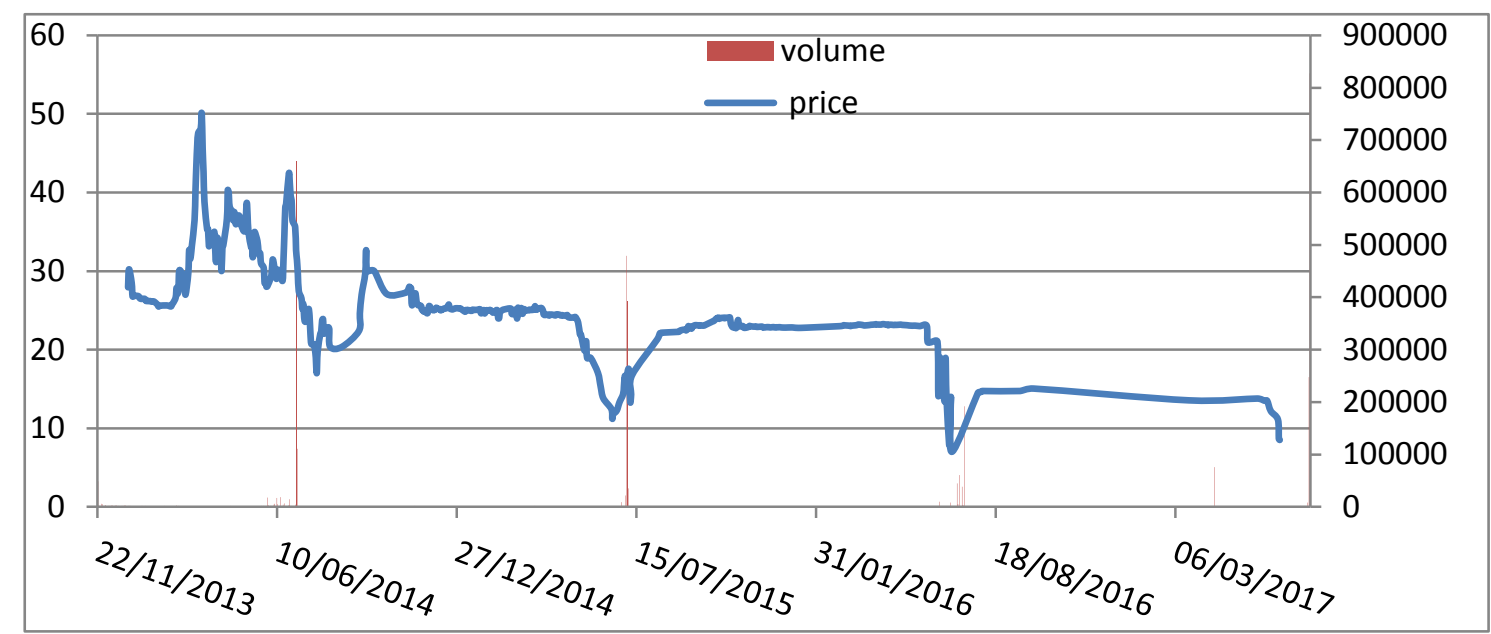


Figure 8

Chongqing's Carbon Spot Price and Volume

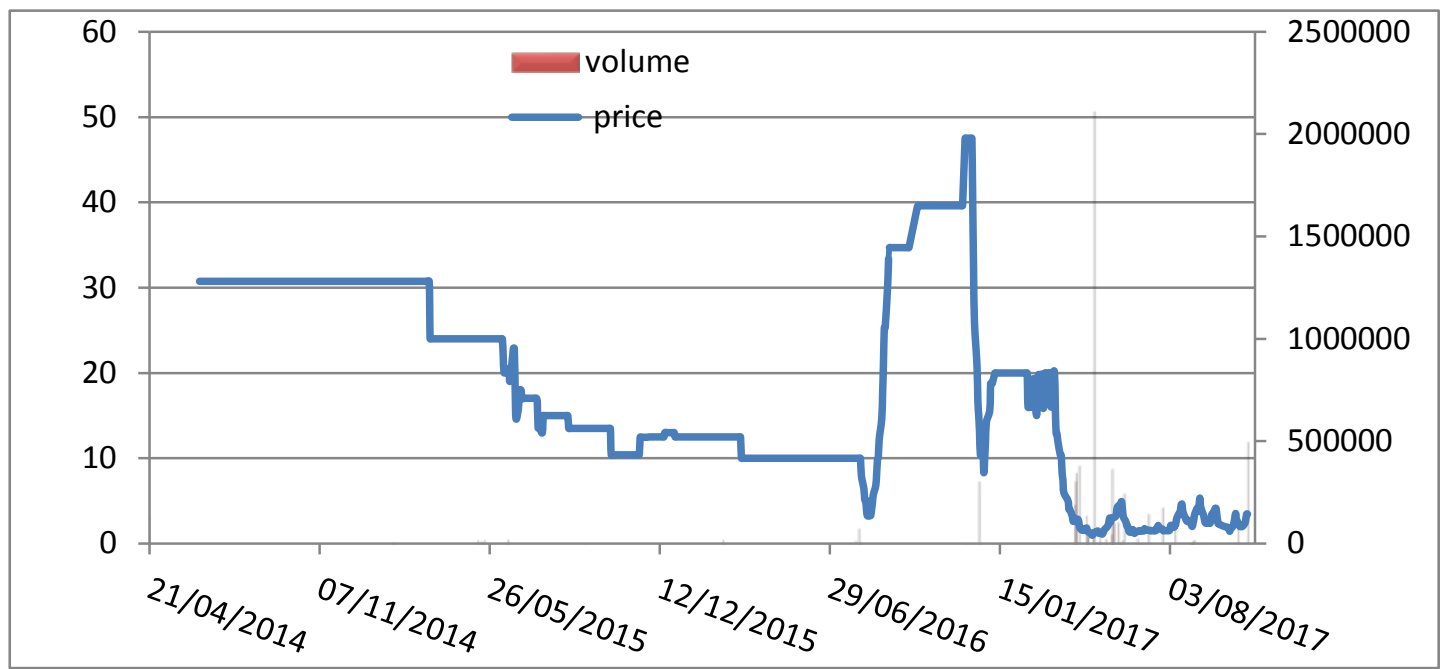


Figure 9

Hubei's Carbon Spot Price and Volume

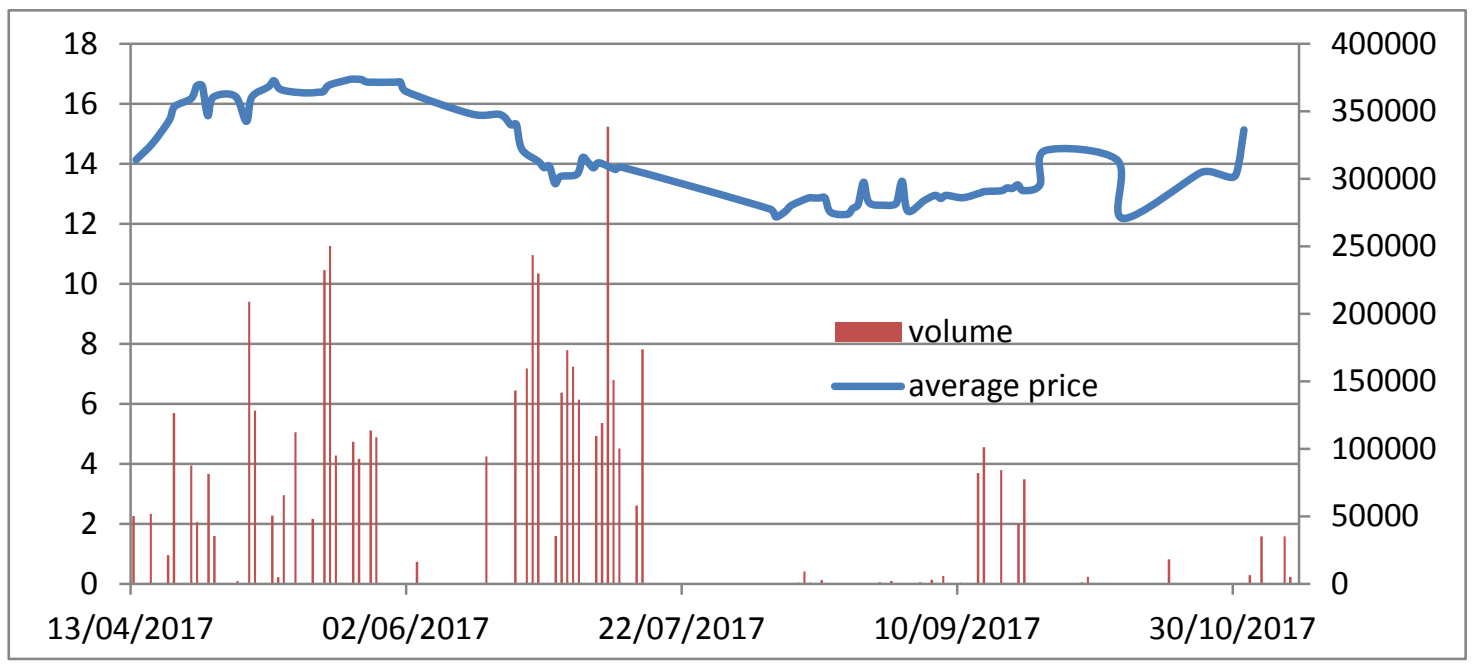


Figure 10

Fujian's Carbon Spot Price and Volume

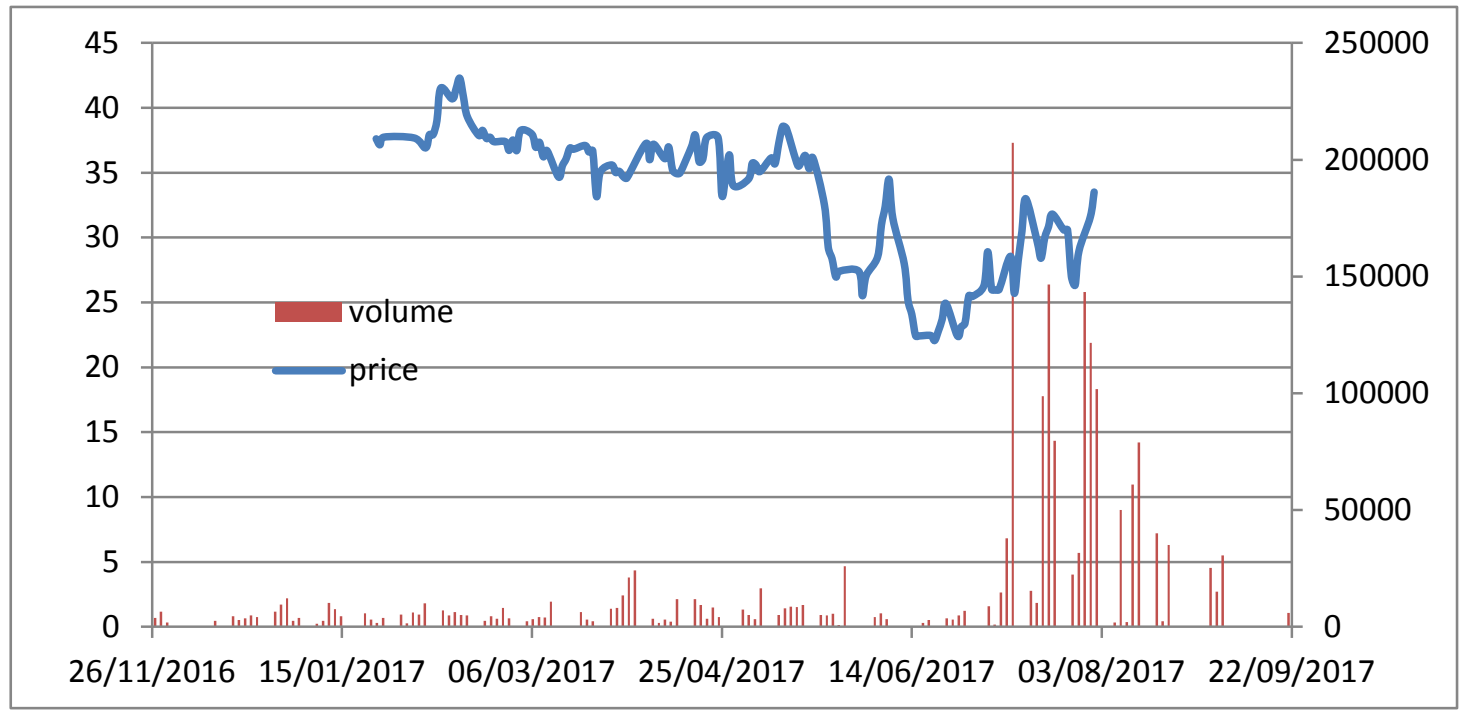


Figure 11

Trade Turnovers of Seven Markets, 2014-2017

2014

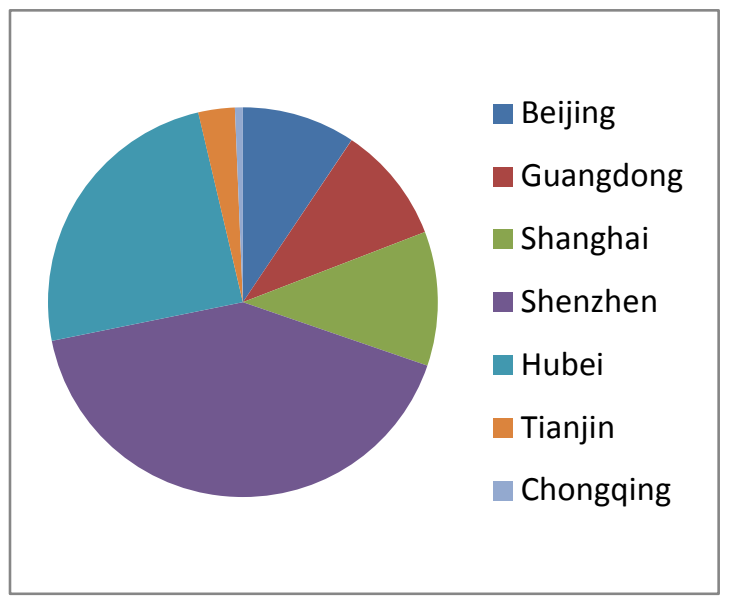

2016

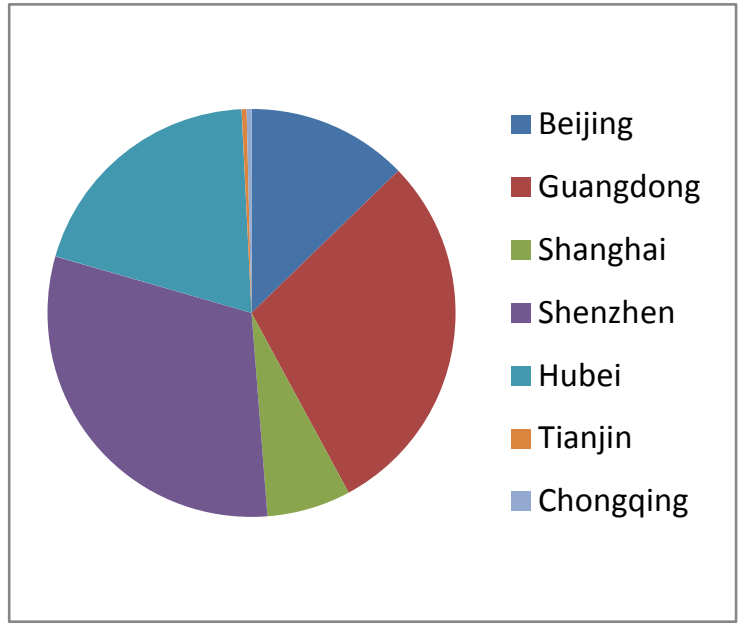

2015

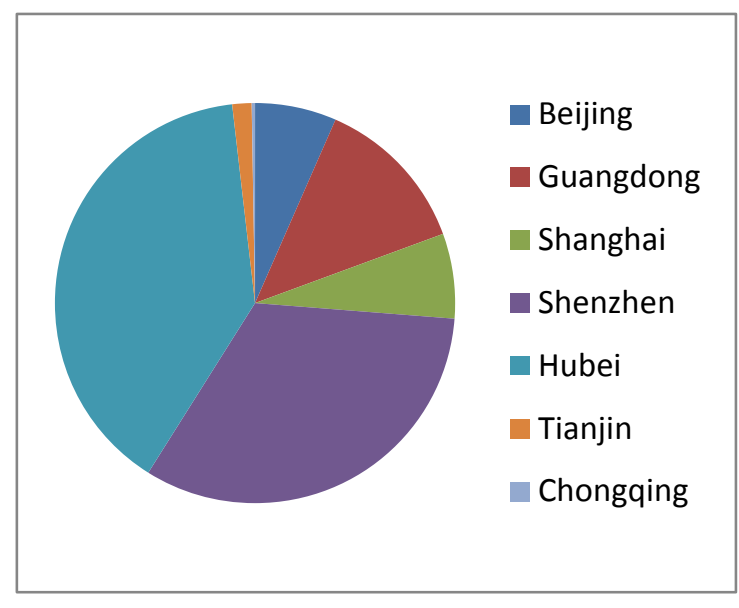

2017

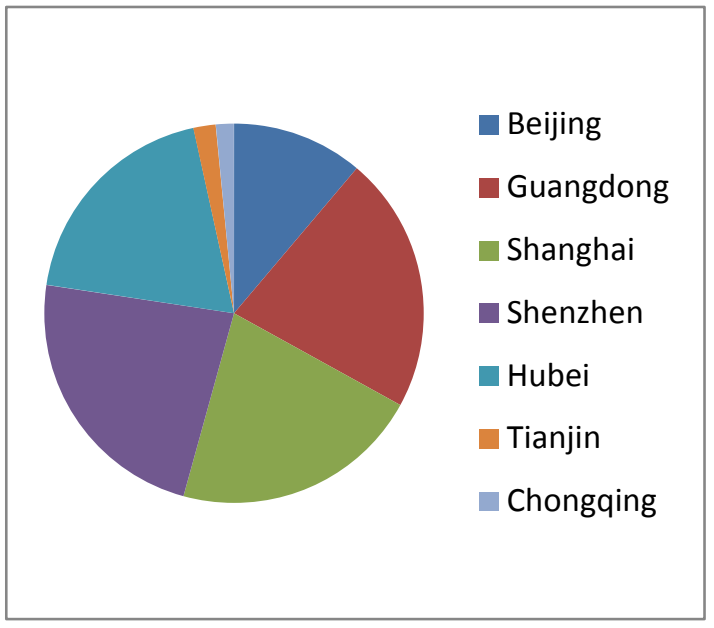


Figure 12

Trade Volumes (\%) of Seven Markets, 2014-2017

2014

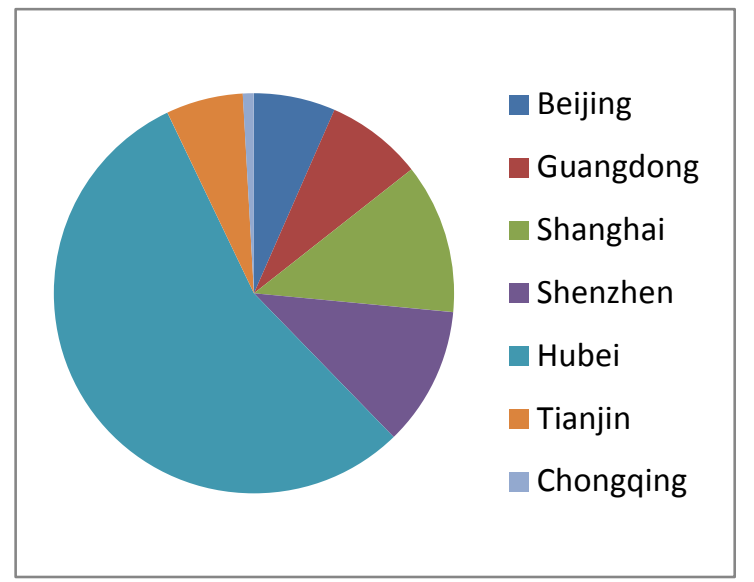

2016

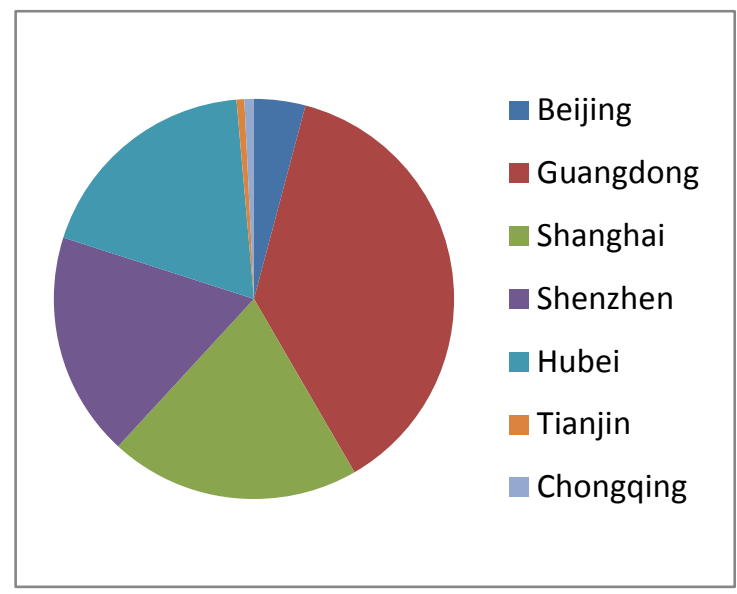

2015

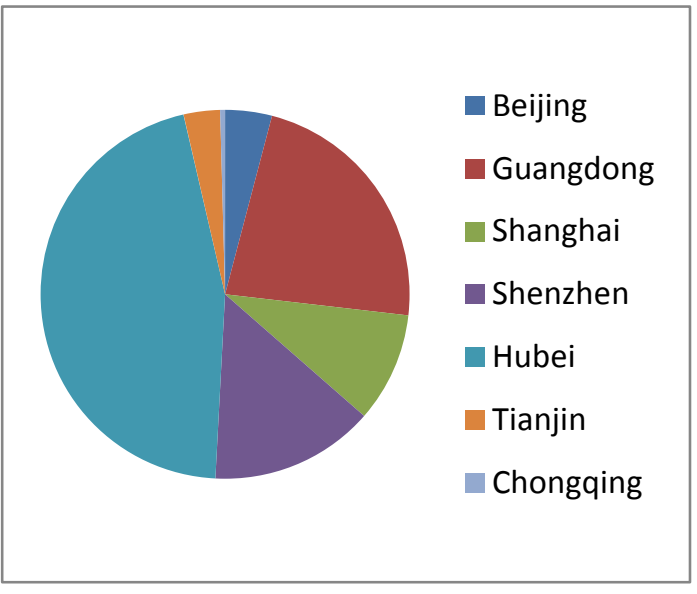

2017

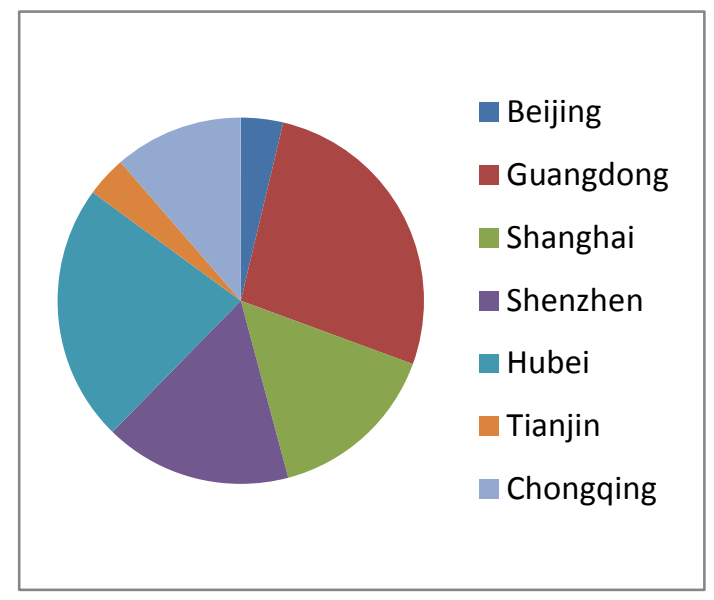




\section{References}

Chang, C.-C. (2010), “A Multivariate Causality Test of Carbon Dioxide Emissions, Energy Consumption and Economic Growth in China”, Applied Energy, 87, 35333537.

Chang, C.-L., M. McAleer and G.D. Zuo (2017), "Volatility Spillovers and Causality of Carbon Emissions, Oil and Coal Spot and Futures for the EU and USA", Sustainability, 9(10:1789), 1-21.

Chen, W. (2005), “The Costs of Mitigating Carbon Emissions in China: Findings from China MARKAL-MACRO Modeling”, Energy Policy, 33(7), 885-896.

Daskalakis, G. and R. Markellos (2009), “Are Electricity Risk Premia Affected by Emission Allowance Prices? Evidence from the EEX, Nord Pool and Powernext”, Energy Policy, 37(7), 2594-2604.

Daskalakis G., D. Psychoyios, and R.N. Markellos (2009), "Modeling CO2 Emission Allowance Prices and Derivatives: Evidence from the European Trading Scheme”, Journal of Banking \& Finance, 33, 1230-1241.

Gregg, J.S., R.J. Andres, and G. Marland (2008), "China: Emissions Pattern of the World Leader in CO2 Emissions from Fossil Fuel Consumption and Cement Production”, Geophysical Research Letters, 35, L08806, 1-5.

Li, J. and M. Colombier (2009), "Managing Carbon Emissions in China Through Building Energy Efficiency”, Journal of Environmental Management, 90(8), 2436-2447.

Liu, L., C. Chen, Y. Zhao, and E. Zhao (2015), “China’s Carbon-emissions Trading: Overview, Challenges and Future”, Renewable and Sustainable Energy Reviews, 49, 254-266.

Nam, K.-M., C.J. Waugh, S. Paltsev, J.M. Reilly, and V.J. Karplus (2014), “Synergy Between Pollution and Carbon Emissions Control: Comparing China and the United States”, Energy Economics, 46, 186-201. 
Tang, L., J. Wu, L. Yu, and Q. Bao (2015), "Carbon Emissions Trading Scheme Exploration in China: A Multi-agent-based Model”, Energy Policy, 81, 152-169.

Xiong, L., B. Shen, S. Qi, L. Price, and B. Ye (2017), “The Allowance Mechanism of China's Carbon Trading Pilots: A Comparative Analysis with Schemes in EU and California”, Applied Energy, 185, 1849-1859.

Zhang, Y. (2015), "Reformulating the Low-Carbon Green Growth Strategy in China”, Climate Policy, 15, 40-59.

Zhang D., V. Karplus, C. Cassisa, and X. Zhang (2014), "Emissions Trading in China: Progress and Prospects”, Energy Policy, 75, 9-16.

Zhang Y.J. and Y.F. Sun (2016), “The Dynamic Volatility Spillover between European Carbon Trading Market and Fossil Energy Market”, Journal of Cleaner Production, 112(4), 2654-2663.

Zhang, Y.-J., A.D. Wang, and Y.-B. Da (2014), "Regional Allocation of Carbon Emission Quotas in China: Evidence from the Shapley Value Method”, Energy Policy, 74, 454-464. 


\section{Data References}

1. National Bureau of Statistics of People's Republic of China. http://www.stats.gov.cn/tjsj/

2. China National Development and Reform Commission. http://www.ndrc.gov.cn/

3. Guangdong Provincial Bureau of Statistics. http://www.gdstats.gov.cn/

4. Shenzhen Bureau of Statistics. http://www.sztj.gov.cn/

5. Shanghai Bureau of Statistics. http://www.stats-sh.gov.cn/

6. Beijing Bureau of Statistics. http://www.bjstats.gov.cn/

7. Tianjin Bureau of Statistics. http://www.stats-ti.gov.cn/

8. Hubei Provincial Bureau of Statistics. http://www.stats-hb.gov.cn/

9. Chongqing Bureau of Statistics. http://www.cati.gov.cn/

10. Fujian Provincial Bureau of Statistics. http://www.stats-fj.gov.cn/

11. China Shenzhen Emission Exchange. http://www.cerx.cn/

12. China Guangzhou Emission Exchange. http://www.cnemission.com/

13. China Beijing Environment Exchange. http://www.cbeex.com.cn/

14. Shanghai Environment and Energy Exchange. http://www.cneeex.com/

15. China Tianjin Emission Exchange. http://www.chinatcx.com.cn/tcxweb/

16. China Hubei Emission Exchange. http://www.hbets.cn/index.php/

17. Chongqing Carbon Emissions Trading Center. http://tpf.cqggzy.com/

18. Carbon Emissions Trading. http://www.tanpaifang.com/

19. Hong Kong Emissions Exchange. http://www.hex.com.hk/ 